\title{
Sandwich Panel Cores for Blast Applications: Materials and Graded Density
}

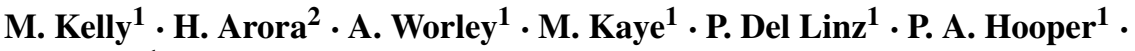 \\ J. P. Dear ${ }^{1}$
}

Received: 3 February 2015 / Accepted: 15 June 2015 / Published online: 4 August 2015

(C) Society for Experimental Mechanics 2015

\begin{abstract}
Sandwich composites are of interest in marine applications due to their high strength-to-weight ratio and tailorable mechanical properties, but their resistance to air blast loading is not well understood. Full-scale $100 \mathrm{~kg}$ TNT equivalent air blast testing at a $15 \mathrm{~m}$ stand-off distance was performed on glass-fibre reinforced polymer (GFRP) sandwich panels with polyvinyl chloride (PVC); polymethacrylimid (PMI); and styrene acrylonitrile (SAN) foam cores, all possessing the same thickness and density. Further testing was performed to assess the blast resistance of a sandwich panel containing a stepwise graded density SAN foam core, increasing in density away from the blast facing side. Finally a sandwich panel containing compliant polypropylene (PP) fibres within the GFRP front face-sheet, was subjected to blast loading with the intention of preventing front face-sheet cracking during blast. Measurements of the sandwich panel responses were made using high-speed digital image correlation (DIC), and post-blast damage was assessed by sectioning the sandwich panels and mapping the
\end{abstract}

\footnotetext{
J. P. Dear

j.dear@imperial.ac.uk

H. Arora

hari.arora04@imperial.ac.uk

P. A. Hooper

paul.hooper@imperial.ac.uk
}

1 Department of Mechanical Engineering, Imperial College London, London, SW7 2AZ, UK

2 The Royal British Legion Centre for Blast Injury Studies and Department of Bioengineering, Imperial College London, London, SW7 2AZ, UK damage observed. It was concluded that all cores are effective in improving blast tolerance and that the SAN core was the most blast tolerant out of the three foam polymer types, with the DIC results showing a lower deflection measured during blast, and post-blast visual inspections showing less damage suffered. By grading the density of the core it was found that through thickness crack propagation was mitigated, as well as damage in the higher density foam layers, thus resulting in a smoother back face-sheet deflection profile. By incorporating compliant PP fibres into the front face-sheet, cracking was prevented in the GFRP, despite damage being present in the core and the interfaces between the core and face-sheets.

Keywords Graded density core - Foam core polymer type - Digital image correlation - Air blast loading . Compliant face-sheet

\section{Introduction}

The high strength-to-weight ratio and tailorable mechanical properties of polymeric sandwich composites makes them attractive for marine applications. In some scenarios it is also important that these materials are tested under blast loading conditions. This area of research is still not fully understood and the research presented in this paper considers the effect on panel response of three different foam core polymer types for use in sandwich composites: polyvinyl chloride (PVC); polymethacrylimid (PMI); and styrene acrilonitrile (SAN). Further blast testing also considered using three SAN foam layers of equal thickness but varying density arranged through the core thickness so that the lowest density sheet is on the blast side, and the highest is on the opposite face. Finally, testing was 
performed with polypropelene (PP) fibre layers interspersed between the glass fibre layers in the blast face, to reduce front face damage during blast loading. Arora et al. [1] performed full-scale air blast testing on glass fibre reinforced polymer (GFRP) skin sandwich composites with $40 \mathrm{~mm}$ thick styrene acrylonitrile (SAN) foam cores, implementing $30 \mathrm{~kg}$ Composition 4 (C4) plastic explosive. The response of these test panels was measured using digital image correlation (DIC). This provided the responses of the SAN sandwich panels under relatively low charge sizes, whereas in the research presented in this paper the panels are subjected to much larger charge sizes. Arora et al. [2] performed further full-scale air blast research considering the effect of sandwich core thickness on panel response, and also performed underwater blast testing on polymeric foam sandwich panels and GFRP tubular structures. This provides experimental validation of the effect of changing core thickness, a factor in the research presented in this paper. Latourte et al. [3] also performed underwater impulsive loading tests on sandwich composite structures in order to determine failure mechanisms, the pressure loading being of high peak pressure and lower impulse, meaning that the core was crushed upon initial arrival of the blast wave. Small scale air blast testing was performed by Zhu et al. [4] in which honeycomb and aluminium foam metallic sandwich panels were suspended in front of a trinitrotoluene (TNT) charge, the responses of which were compared to an analytical model incorporating three phases of deformation in the sandwich panels: front face deformation; core crushing; and bending. The effect of a close-in small charge means that non-planar loading is achieved on the face sheet, causing more complex damage mechanisms in the sandwich panel. Gardner et al. [5] considered the use of graded densities of SAN foam sheets within one sandwich composite core, in order to determine the effect on the blast response of having a graded increase of density away from the blast wave face. It was found that the lower density foam layers attenuated the blast wave, as the peak pressures were high enough to crush the core. Flexural testing of graded density cores was performed by Gupta et al. [6] in which syntactic foam beams were produced with microspheres of varying wall thickness through the beam thickness, and tested under flexural loading, in order to further understand the effect of grading the density of the foam through the beam thickness. The response of PVC foam core sandwich panels to blast loading have been researched analytically by Hoo Fatt and Palla [7], where the response was broken down into through thickness wave prorogation leading to core crushing, and then global bending of the sandwich panel. PVC foam cores were also considered analytically by Andrews and Moussa [8] in which damage was predicted in the form of skin wrinkling, skin tensile failure or core shear failure during the bending phase of blast loading, similar to the different failure mechanisms observed in air blast loading. PMI polymer cores were tested by Shipsha and Zenkert [9] using low velocity semi-spherical impact, in order to determine the reduction in edgewise compression strength after impact. Arora et al. [10] performed full-scale $100 \mathrm{~kg}$ TNT blast testing on GFRP and carbon fibre reinforced polymer (CFRP) sandwich panels using SAN foam cores, and used these experimental results to validate finite element (FE) predictions on blast response. SAN foam cores have also been researched by Jackson and Shukla [11] where specimens were blast tested after receiving impacts from high velocity projectiles, or low velocity drop weights, in order to determine the residual blast resistance of the sandwich panels. Similar SAN foam core sandwich panels were also tested by Wang and Shukla [12] in which the blasted sandwich panels had in-plane compression loading during impact. The research presented in this paper directly compares the response of $40 \mathrm{~mm}$ thick PVC, PMI and SAN foam cores of $100 \mathrm{~kg} / \mathrm{m}^{3}$ density to a $100 \mathrm{~kg}$ TNT equivalent blast. As shown by Viot [13], polymeric foam behaviour varies dramatically with increased loading rates, so the research presented in this paper investigates the different blast responses of foams with similar quasi-static mechanical properties, but with different dynamic material properties and varying polymer types. Dynamic studies have been performed on all three polymer types studied in this research, an example of which is the low velocity drop weight tests performed by Leijten et al. [14], on PMI foam core sandwich panels for use in aircraft. The foams used in this research have also been tested in high rate, the results of which are presented in this paper. The research also presents a comparison of the aforementioned $40 \mathrm{~mm}$ SAN foam sandwich panel to a sandwich panel containing three $10 \mathrm{~mm}$ thick layers of SAN foam of $100 \mathrm{~kg} / \mathrm{m}^{3}, 130 \mathrm{~kg} / \mathrm{m}^{3}$ and $200 \mathrm{~kg} / \mathrm{m}^{3}$ density, petitioned in increasing density order from the front face (blast side) to the rear face. These two sandwich panels had equal areal densities. The final comparison presented in this paper is of two panels containing $40 \mathrm{~mm}$ thick PVC foam cores of $100 \mathrm{~kg} / \mathrm{m}^{3}$ density, one panel having face-sheets of plain, unidirectional GFRP and the other panel having woven PP fibre layers interspersed between the unidirectional E-glass fibre layers in the front face-sheet, in order to prevent front face-sheet compressive failure during blast. The responses of all of these test panels were measured using DIC, and the post-blast damage was assessed by sectioning the blast panels to visually inspect the defects.

\section{Materials}

All sandwich panels tested in this research consisted of polymeric foam cores, with eight ply GFRP face-sheets either side. It was decided to use GFRP specifically as this is 
Fig. 1 Schematic of the three sandwich panel types. (a) $40 \mathrm{~mm}$ thick single density foam core; (b) $30 \mathrm{~mm}$ thick graded density foam core; (c) Compliant face-sheet sandwich panel

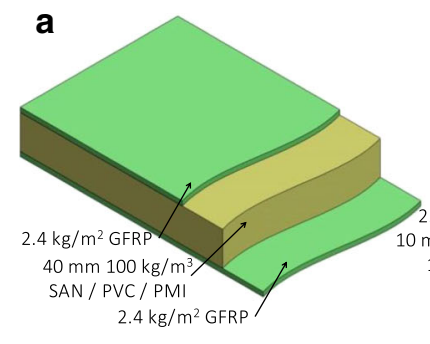

b

b

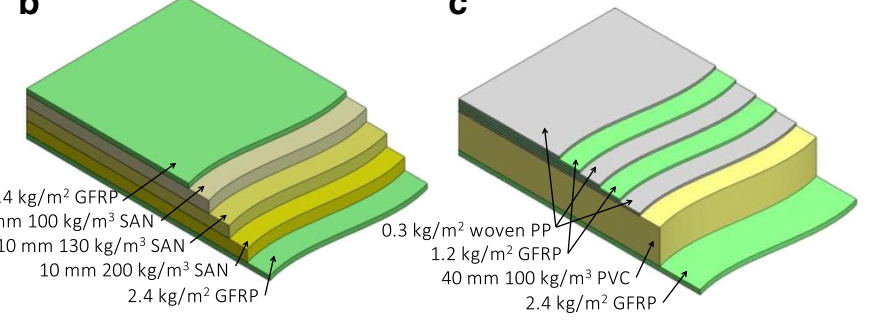

already a well established marine material. Another option was to construct the sandwich panels with carbon fibre reinforced polymer (CFRP) face-sheets, however, the goal of this research was to study the effect of core damage on panel response, so the maximum amount of bending during blast was required, making GFRP favourable due to it's lower stiffness. Due to other unrelated testing being performed at DNV GL simultaneously, the charge size was set at $100 \mathrm{~kg}$ TNT equivalent. With this in mind it was necessary to decide upon a stand-off distance and a GFRP face-sheet construction which would cause core cracking, but not back face-sheet tensile damage during blast, which would jeopardise the safety of high speed camera equipment situated in the test cubicle behind the sandwich panels. Arora, Hooper and Dear [1] performed a full scale air blast test using a $25 \mathrm{~mm}$ SAN M130 foam core at a stand-off distance of $14 \mathrm{~m}$ from a $100 \mathrm{~kg}$ TNT equivalent charge, which had two plies of quadriaxial GFRP face-sheets either side, and this produced core cracking and front face-sheet compressive damage, but no rear face damage. Based on these results it was decided to use two plies of quadriaxial QE1200 face-sheets on either side of the blast panel with $30 \mathrm{~mm}$ and $40 \mathrm{~mm}$ thick cores, and use an analytical

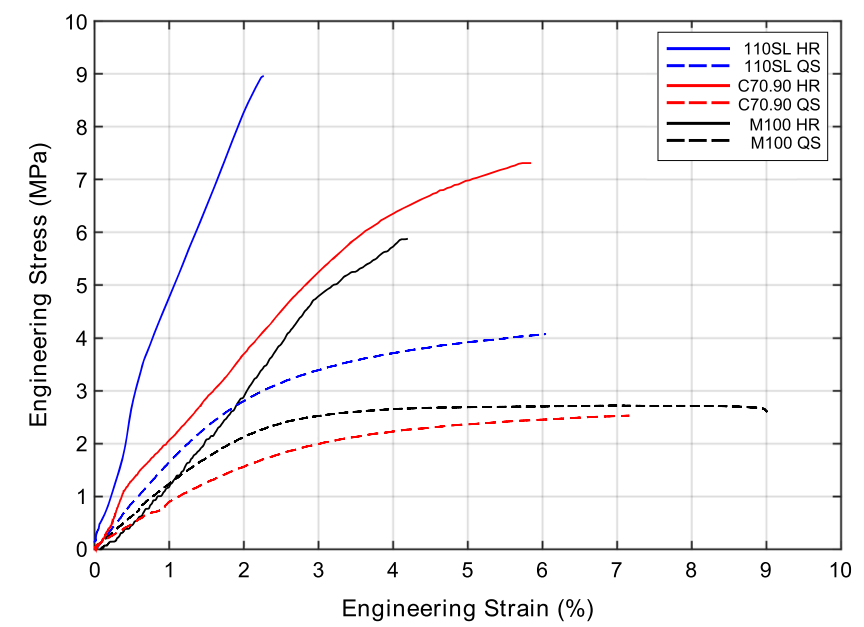

Fig. 2 Tensile engineering stress versus engineering strain for the 110SL PMI; C70.90 PVC and M100 SAN foams used in the polymer comparison sandwich panels, as well as the compliant face-sheet sandwich panel. The high rate (HR) tests were at $180 \mathrm{~s}^{-1}$, and also shown are quasi-static $(\mathrm{QS})$ tensile test results solution to determine the stand-off distance of the sandwich panel from the charge. Thicker foam cores were used to generate greater shear strains in the materials, to better understand the failure mechanisms of the different polymers. Andrews and Moussa [8] developed analytical solutions to predict damage in foam core sandwich panels, based on the natural frequency of the panel and the blast wave parameters, which was used to determine the stand-off distance in these tests.

\section{Foam Material Properties}

A schematic of all three sandwich panel types is shown in Fig. 1, with Fig. 1(a) showing the single density foam core sandwich panels; Fig. 1(b) showing the graded density foam sandwich panel; and Fig. 1(c) showing the compliant face-sheet sandwich panel. From blast testing performed by Arora et al [1], it was estimated that the tensile strain rate of the sandwich panel during blast was approximately $10^{-1}$, based on the maximum principal strain measured on the back face-sheet using DIC. The was taken for a smaller charge size, but with a core thickness of $40 \mathrm{~mm}$, and calculated by dividing the peak tensile strain by the time to

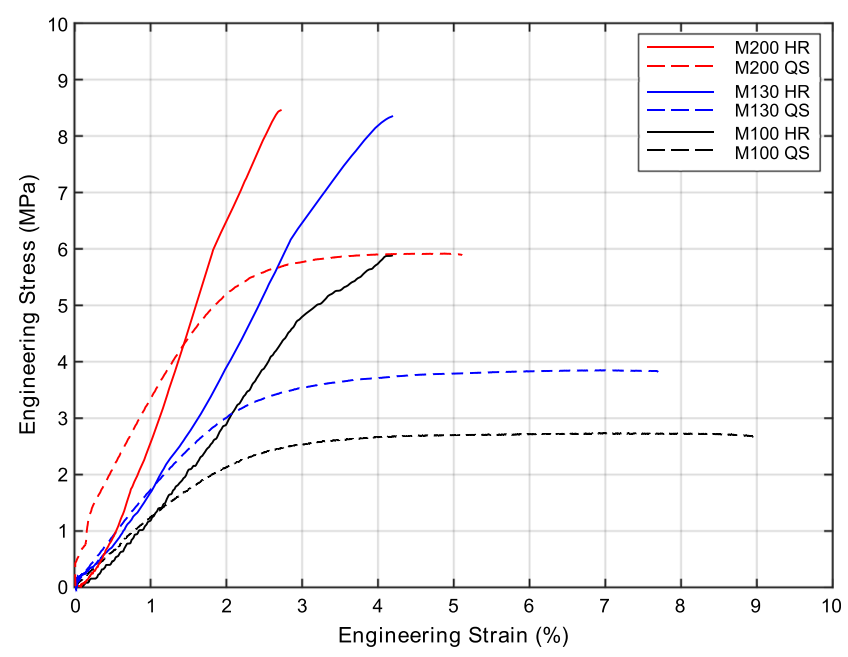

Fig. 3 Tensile engineering stress versus engineering strain for the M100 SAN; M130 SAN and M200 SAN foams used in the graded density sandwich panels. The high rate (HR) tests were at $180 \mathrm{~s}^{-1}$, and also shown are quasi-static (QS) tensile test results 
Table 1 Tensile mechanical properties of the various foam polymers used as sandwich panel cores in this research. Properties are shown for testing at quasi-static (QS) rates and at $180 \mathrm{~s}^{-1}(\mathrm{HR})$

\begin{tabular}{lllll}
\hline Material & $\begin{array}{l}\text { Density } \\
\left(\mathrm{kg} / \mathrm{m}^{3}\right)\end{array}$ & $\begin{array}{l}\text { QS/HR elastic } \\
\text { modulus } \\
(\mathrm{MPa})\end{array}$ & $\begin{array}{l}\text { QS/HR tensile } \\
\text { breaking } \\
\text { stress (MPa) }\end{array}$ & $\begin{array}{l}\text { QS/HR tensile } \\
\text { breaking } \\
\text { strain }(\%)\end{array}$ \\
\hline M100 SAN & $108^{\mathrm{a}}$ & $107 / 143$ & $2.69 / 5.67$ & $7.82 / 5.66$ \\
M130 SAN & $140^{\mathrm{a}}$ & $161 / 245$ & $3.70 / 7.81$ & $7.26 / 3.67$ \\
M200 SAN & $200^{\mathrm{a}}$ & $258 / 438$ & $5.63 / 8.44$ & $5.57 / 2.06$ \\
C70.90 PVC & $100^{\mathrm{b}}$ & $80.0 / 177$ & $2.73 / 7.84$ & $9.38 / 4.43$ \\
110SL PMI & $110^{\mathrm{c}}$ & $156 / 462$ & $3.89 / 8.71$ & $5.59 / 2.06$
\end{tabular}

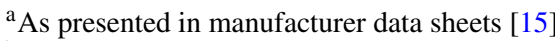

${ }^{\mathrm{b}}$ As presented in manufacturer data sheets [16]

${ }^{c}$ As presented in manufacturer data sheets [17]

reach this value. Characterisation of all four foam polymers have been performed at quasi-static and dynamic rates, to determine how the mechanical properties vary. Tensile engineering stress versus engineering strain curves for the 110SL PMI; C70.90 PVC and M100 SAN foam polymers at a quasi-static rate (QS) and high rate (HR) can be seen in Fig. 2, and the tensile curves for the M100; M130 and M200 SAN foam polymers are shown in Fig. 3. Table 1 provides a summary of the material properties of the foam polymers used in this research.

\section{Face-Sheet Properties}

The face-sheets used in the polymer comparison and graded density sandwich panel were two plies of QE1200 quadriaxial GFRP either side, infused with Ampreg22 resin. This was produced using vacuum consolidation, where the GFRP fibres and core were coated in resin, before being held under vacuum at $85^{\circ} \mathrm{C}$ for 12 hours. In the case of the graded density core, resin was also used to bond the foam layers together. This section provides the mechanical properties of the GFRP face-sheets, and of the face-sheet containing PP fibres. Table 2 provides material properties of each constitutive material in the GFRP and PP plies, as well as the bulk material properties for the QE1200 plies and the woven PP plies. In order to calculate the bulk mechanical properties of the GFRP plies, a rule of mixtures was used, with a Kenchal factor of 0.375 to represent the eight quadriaxial plies, with a layup order of 0/90/-45/+45/+45/-45/90/0 Foam Core - 0/90/-45/+45/+45/-45/90/0. Based on each plie of the QE1200 layer being $0.25 \mathrm{~mm}$ thick when cured, it was possible to calculate a fibre volume fraction of 0.47 . The Kenchal factor for the woven PP plies is 0.5 , and the fibre volume fraction was estimated to be 0.62 , as taken from the manufacturer data sheet [18].

\section{Interfaces}

The adhesion of the face-sheets to the foam cores, and of the foam layers in the graded density core sandwich panel, was by the Ampre22 resin. The panels were constructed using vacuum consolidation, meaning that each fibre ply, and each side of the foam layers were coated in resin, before being cured under vacuum at $85^{\circ} \mathrm{C}$ for 12 hours. As will be shown in "Results" section, the modes of failure in the sandwich panels are core cracking, interface debonding and front face-sheet compressive cracking. This debonding takes the form of mode II fracture, as it is caused by shear at the interfaces during panel bending. The inter-laminar shear strength of the resin is 53.3 MPa, as shown in Table 2, but the actual strength of the interface will be less, due to the failure path being within the first layer of cells of the foam core.

\section{Experimental}

Blast testing was performed at the DNV GL Spadeadam test site, and this section of the paper describes the three separate studies performed. Also explained here are the experimental setup and the data acquisition methods utilised. Table 3

Table 2 Details of the GFRP constitutive material properties, and the bulk material properties of the QE1200 plies and the PP plies

\begin{tabular}{llllll}
\hline Material & Density $\left(\mathrm{kg} / \mathrm{m}^{3}\right)$ & $\begin{array}{l}\text { Elastic modulus } \\
(\mathrm{GPa})\end{array}$ & $\begin{array}{l}\text { Tensile breaking } \\
\text { stress (MPa) }\end{array}$ & $\begin{array}{l}\text { Inter-laminar shear } \\
\text { strength (MPa) }\end{array}$ & $\begin{array}{l}\text { Compressive } \\
\text { strength (MPa) }\end{array}$ \\
\hline Glass fibres & $2550^{\mathrm{a}}$ & $80^{\mathrm{a}}$ & $2000^{\mathrm{a}}$ & - & $1450^{\mathrm{b}}$ \\
Amreg22 resin & $1140^{\mathrm{c}}$ & $3.74^{\mathrm{c}}$ & $72.2^{\mathrm{c}}$ & $53.3^{\mathrm{c}}$ & $462^{\mathrm{c}}$ \\
QE1200 quadriaxial GFRP Ply & 1803 & 16 & 391 & 53.3 & 385 \\
Innegra IS-940 PP fibres & - & $14.8^{\mathrm{d}}$ & $667^{\mathrm{d}}$ & - & - \\
Woven Innegra PP ply & - & 6.02 & 234 & 53.3 & 462 \\
\hline
\end{tabular}

a As presented in online data sheets [19]

${ }^{b}$ As published by Soden et al. [20]

${ }^{c}$ As presented in manufacturer data sheets [15]

${ }^{\mathrm{d}}$ As presented in manufacturer data sheets [18] 
Table 3 Details of the sandwich panel thickness, areal density and the speed of the high speed cameras used in the test

\begin{tabular}{llll}
\hline Name & $\begin{array}{l}\text { Sandwich panel } \\
\text { core thickness } \\
(\mathrm{mm})\end{array}$ & $\begin{array}{l}\text { Areal density } \\
\left(\mathrm{kg} / \mathrm{m}^{2}\right)\end{array}$ & $\begin{array}{l}\text { Frame rate } \\
\text { of the camera } \\
\left(\mathrm{s}^{-1}\right)\end{array}$ \\
\hline M100 SAN Core & 40 & 8.8 & 5400 \\
C70.90 PVC Core & 40 & 8.8 & 5400 \\
110SL PMI Core & 40 & 8.8 & 5400 \\
Graded SAN Core & 30 & 9.1 & 7000 \\
PP Interlayer & 40 & 9.7 & 7000 \\
\hline
\end{tabular}

Provides details of the various sandwich panels tested in this research, the foam core thickness and areal density of the sandwich panel, and the high speed camera frame rate used to measure the panel deflection.

\section{Varying Polymer Type Study}

The first blast test study considered three sandwich panels of equivalent density and thickness, with different foam polymer cores. These were: SAN; PVC; and PMI. The goal of these tests were to determine the responses of different foam polymers to blast loading. Table 1 shows that the foam materials have significantly different properties at quasi-static and high rates. When used as core materials, the important material property is the strain to failure of the material, as the stiffness of the core is small in comparison to the face-sheets. This research aims to consider the various failure patterns of the foam cores, and the interfaces between the cores and the face-sheets, during blast.

\section{Graded Density Core Study}

The purpose of using a graded density foam core in blast analysis is to reduce back face-sheet damage, which is vital in maintaining the integrity of the naval vessel in a blast event. Gupta et al. [6] utilised graded density cores in blast with high peak pressures, which caused core crushing in the lower density foam layers, thus attenuating blast energy. In air blast, the peak pressure is significantly lower, so core crushing is not a failure mechanism in the foam. However, the boundaries between the foam layers are expected to impede proagation through the core, to reduce overall through-thickness cracks. Furthermore, by placing weaker, lower density foam layers nearer to the front, the crack density is increased at the front of the panel, and reduced at the back, resulting in smoother bending of the rear face. This would have the effect of allowing much higher load to be withstood before failure, were the charge energy great enough.

\section{Polypropelene Interlayer}

Due to the tensile strength of GFRP being greater than the compressive strength, the front face-sheet will fail in compression before the rear face-sheet will fail in tension, for a symmetric composite layup. The goal of impregnating PP plies within the GFRP front face-sheet is to prevent catastrophic front face-sheet failure which is beneficial in naval applications, provided the rear face-sheet is also preserved.

\section{Test Layout}

The charge used in these experiments was nitromethane, and the TNT equivalent charge size was $100 \mathrm{~kg}$. The standoff distance of the charge from the test panels was $15 \mathrm{~m}$, and two panels were situated side by side in the same test cubicle. By using such a large charge size at a $15 \mathrm{~m}$ stand-off, the blast wave loading on the test panels could be assumed to be evenly distributed over the surface. The stand-off distance was selected using the analytical method proposed by Andrews and Moussa [8], which considers a simply supported sandwich panel, and can be used to calculate the deflection required to cause core cracking, front face-sheet compressive failure and rear face-sheet tensile failure. Table 4 Shows the required stand-off distances to cause damage in the three types of polymer foam core, and for the $30 \mathrm{~mm}$ thick M130 SAN core. For this analytical solution, a correction factor of 1.8 times the charge weight is used to account for the charge being close to the ground, as suggested in Smith and Hetherington [21]. Also taken from Smith and Hetherington [21] is the prediction of the blast wave profile, in the form of the Friedlander equation. Furthermore, the solution assumes simply supported boundary conditions. The correction factor of 1.8 is recommended for surface bursts and a quasi-elastic ground surface, where in this research the charge is a height of $1.5 \mathrm{~m}$ from the ground. Also, the actual boundary conditions of the blast panels are quasi-built-in, and the model does not account for a drop in bending stiffness after damage takes place. As these things will cause this solution to be overly conservative, it was decided to use a standoff distance of $17 \mathrm{~m}$ or less, as this would certainly cause core shear and possibly front face-sheet damage. As front face-sheet damage was desired, for validation of finite element studies in later research, the stand-off distance chosen was $15 \mathrm{~m}$.

The cubicle was constructed from a reinforced steel front bolted onto six large concrete culverts, to allow a rigid foundation for the test panels. The charge was raised to $1.5 \mathrm{~m}$ off the ground, above a thick steel plate to provide an elastic foundation to the initial detonation and a reflected pressure gauge was situated on the front of the 
Table 4 Stand-off distance to rear face-sheet tensile failure; core cracking; and front face-sheet compressive failure in the $40 \mathrm{~mm}$ thick SAN, PVC and PMI sandwich panels.

Calculated using the analytical solution by Andrews and Moussa [8]

\begin{tabular}{llll}
\hline Name & $\begin{array}{l}\text { Stand-off distance to } \\
\text { cause rear face-sheet } \\
\text { tensile failure (m) }\end{array}$ & $\begin{array}{l}\text { Stand-off distance } \\
\text { to cause core } \\
\text { cracking }(\mathrm{m})\end{array}$ & $\begin{array}{l}\text { Stand-off distance to } \\
\text { cause front face-sheet } \\
\text { compressive failure (m) }\end{array}$ \\
\hline M100 SAN Core & 17 & 28 & 19 \\
C70.90 PVC Core & 17 & 26 & 20 \\
110SL PMI Core & 17 & 20 & 15 \\
M130 SAN Core & 19 & 27 & 18 \\
\hline
\end{tabular}

test cubicle to provide a value of reflected pressure during the blast loading. The layout of the test pad, along with the locations of the static and reflected pressure gauges, can be seen in Fig. 4. In order to provide quasi-builtin boundary conditions for the sandwich panels, 20 holes were drilled around the perimeter of each panel and $5 \mathrm{~mm}$ thick steel plates were adhered to either side of the panel, with marine grade polyurethane sealant. Steel tubes were also inserted into the holes in the sandwich panels before attaching the steel, to avoid crushing the foam cores when tightening the M10 bolts holding the panels onto the fronts of the test cubicles. This clamping arrangement is shown in Fig. 5.

\section{Instrumentation}

To measure the responses of the sandwich panels to blast loading, the back face-sheets were painted white and then had black speckles randomly applied to the surfaces. Two pairs of high speed cameras were then used to record the deflections of the panels and the back face-sheet strain during testing, using DIC. The high speed cameras used were Photron SA5's, with 1 mega pixel resolution and a frame rate of $7000 \mathrm{~s}^{-1}$, and Photron SA1.1's with 1 mega pixel resolutions and a frame rate of $5400 \mathrm{~s}^{-1}$, the latter having a colour sensor. The cameras were triggered using an open transistor-transistor-logic (TTL) circuit, which was closed by the ionising air caused by the detonation of the explosive charge. Each pair of cameras were also synchronised to ensure that the frames remained aligned after detonation.

\section{Post-Blast Damage Assessment}

To quantify the damage suffered by the sandwich panels during blast loading, they were sectioned into 16 and the edges photographed in order to measure core cracks and debond between the face-sheets and core. The amount of debond present was then quantified as a percentage of the total length of the section edge, and the through thickness core cracks were counted on each edge. The percentage of the section edge containing cracks was also found, to quantify the foam core damage suffered. This method of inspection was chosen due to the difficulties in using other scanning techniques such as X-ray or ultrasonics. The major problem with using X-ray technology is the size of the panels, which would not fit in typical scanners. Ultrasound is a fairly well established scanning technique for composites, but due to the complex structure of the cells in the foam, it is difficult to identify crack surfaces, especially when the cracks have closed again after unloading. The sandwich panels were only sectioned into 16 pieces, as this was deemed enough to produce valuable estimates of the damage suffered in each case, but would leave large enough sections for post-blast strength assessment tests to be performed.
Fig. 4 Schematic of the test pad layout

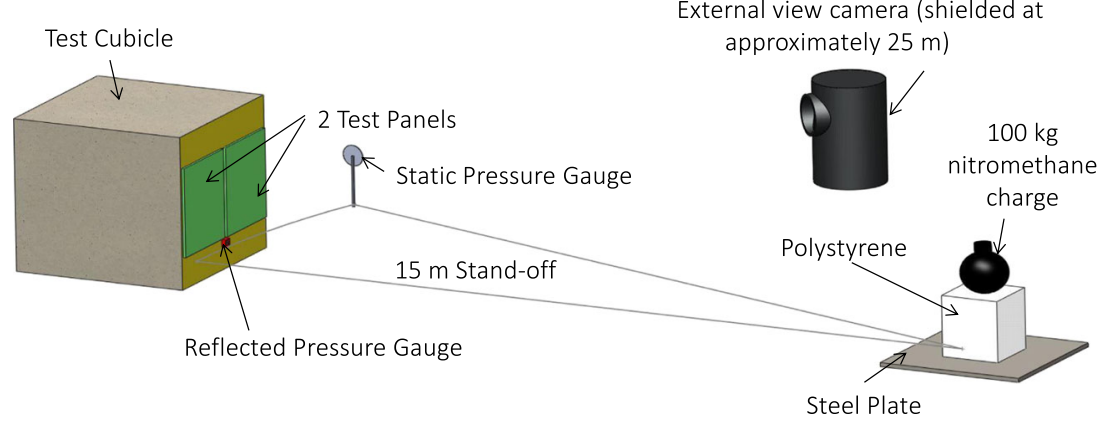




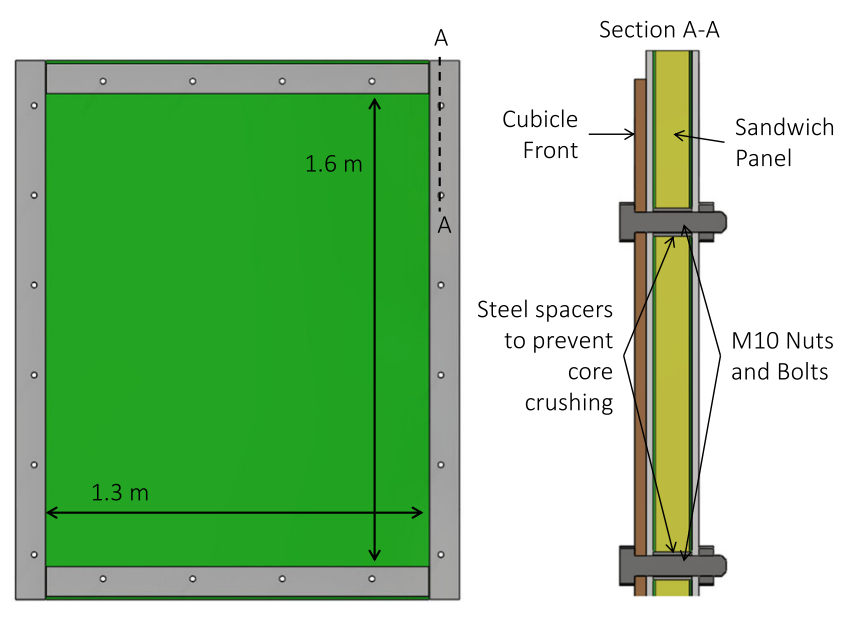

Fig. 5 Schematic of the clamping arrangement of the sandwich panels on the front of the test cubicle

\section{Results}

The two stages of the investigation on the five test panels were to firstly assess their response during blast loading using high-speed DIC, and then to observe the damage suffered by the sandwich panels after blast loading. This section will present the results of these two stages.

\section{Blast Loading Response}

Using two calibrated high speed cameras the response of each sandwich panel to blast loading was measured using DIC. This allowed the out of plane displacement to be determined, as well as the principle strain on the back face of the sandwich panel. Furthermore, a single external Casio EXF1 high speed camera with a resolution of 200,000 pixels, and a frame rate of $300 \mathrm{~s}^{-1}$ recorded the response of the sandwich panel from the outside, and Fig. 6 shows these frames for the PMI foam core panel (panel number 5) and the panel with the front face containing PP fibres (panel number 6). This external view was recorded in each case to ensure there were no unexpected factors influencing the blast test results, such as debris hitting the sandwich panels during the explosion. In order to validate the expected loading on the sandwich panel, static and reflected overpressure gauges were located at the same stand-off distance, the reflected guages allowing the actual loading on the sandwich panels to be determined.

\section{Varying polymer types}

The three foam polymer cores being compared were SAN, PVC and PMI, and their responses to $100 \mathrm{~kg}$ TNT equivalent detonations at $15 \mathrm{~m}$ stand-off distances are shown in this section. The DIC responses of the single layer SAN foam core sandwich panel are shown in Fig. 7(a) illustrates the contour plots of the out of plane displacement $\left(U_{Z}\right)$ and the maximum principal strain $\left(\varepsilon_{\max }\right)$, where discontinuties in displacement, and early concentrated strains are visible along the vertical edges of the panel, indicating core cracking. The central deflection of the SAN core sandwich panel with time is shown in Fig. 7(b) alongside the calculated reflected pressure loading on the sandwich panel, and from this plot the maximum central displacement is $89 \mathrm{~mm}$, the maximum pull-out is $45 \mathrm{~mm}$ and the time period for which the central displacement of the sandwich panel is positive is $12.8 \mathrm{~ms}$. The importance of this final value of period of positive central displacement is that it gives an indication of resdiual stiffness of the panel, after damage has taken place, so a sandwich panel suffering greater
Fig. 6 Frames from the external high speed camera for a blast test containing the PMI foam core sandwich panel, and the compliant face-sheet sandwich panel. Image times are after detonation

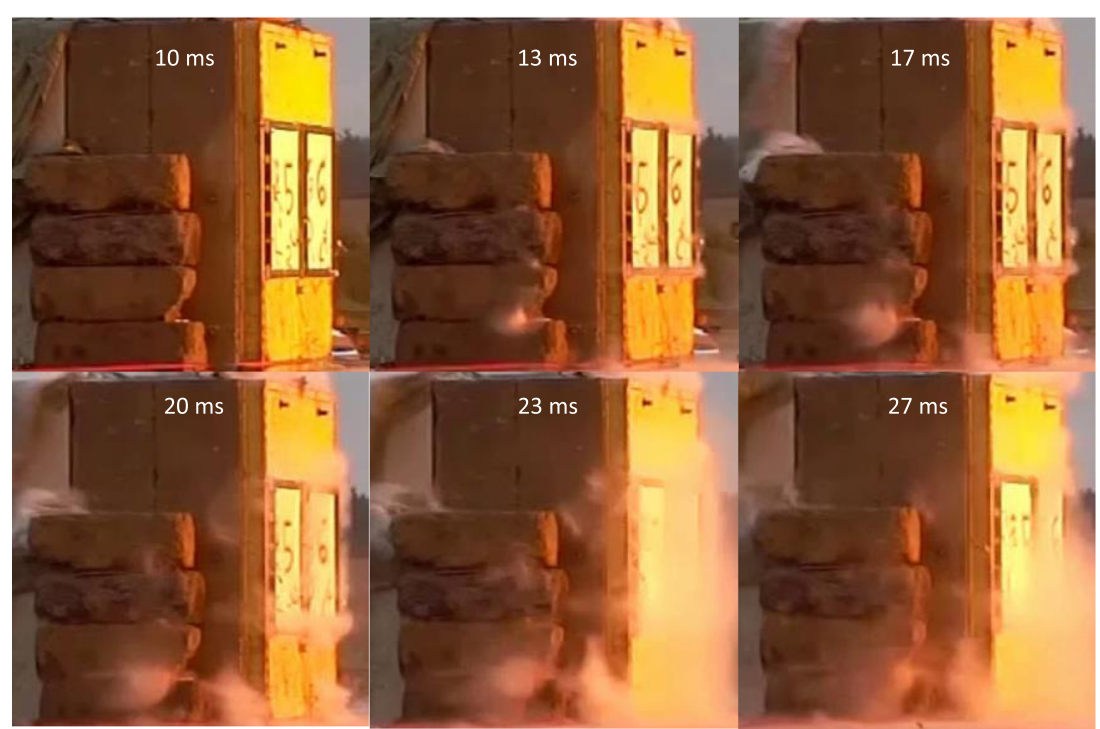



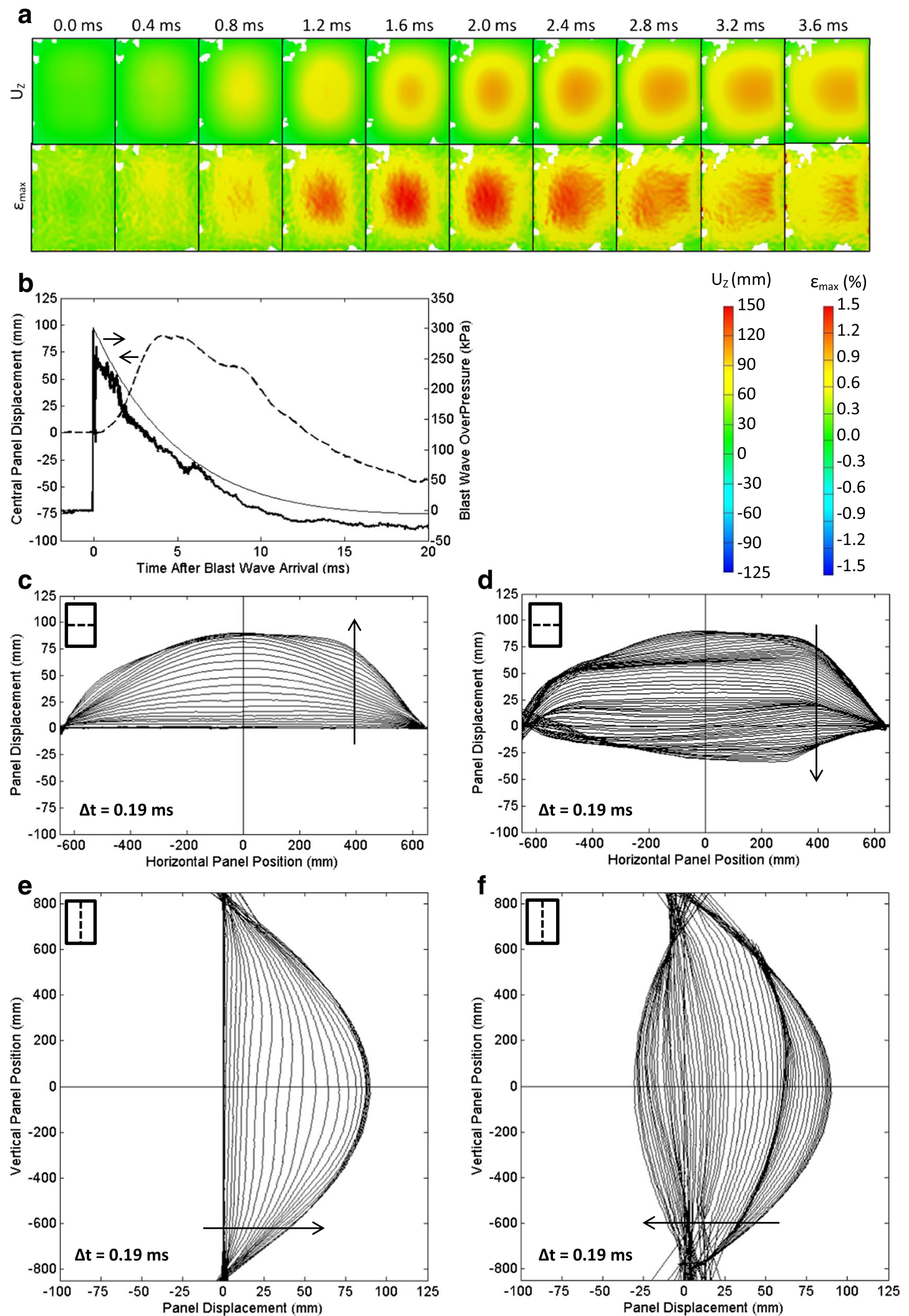

Fig. 7 Response of the single SAN core sandwich panel using DIC: (a) DIC contour plots of out of plane displacement $\left(U_{Z}\right)$ and maximum principal strain $\left(\varepsilon_{\max }\right)$; (b) The central displacement of the sandwich panel (dashed) and the calculated and measured reflected overpressure (solid) with time; (c) The positive phase of the horizontal centre section of the panel; (d) The negative phase of the horizontal centre section of the panel; (e) The positive phase of the vertical centre section of the panel; (f) The negative phase of the vertical centre section of the panel 

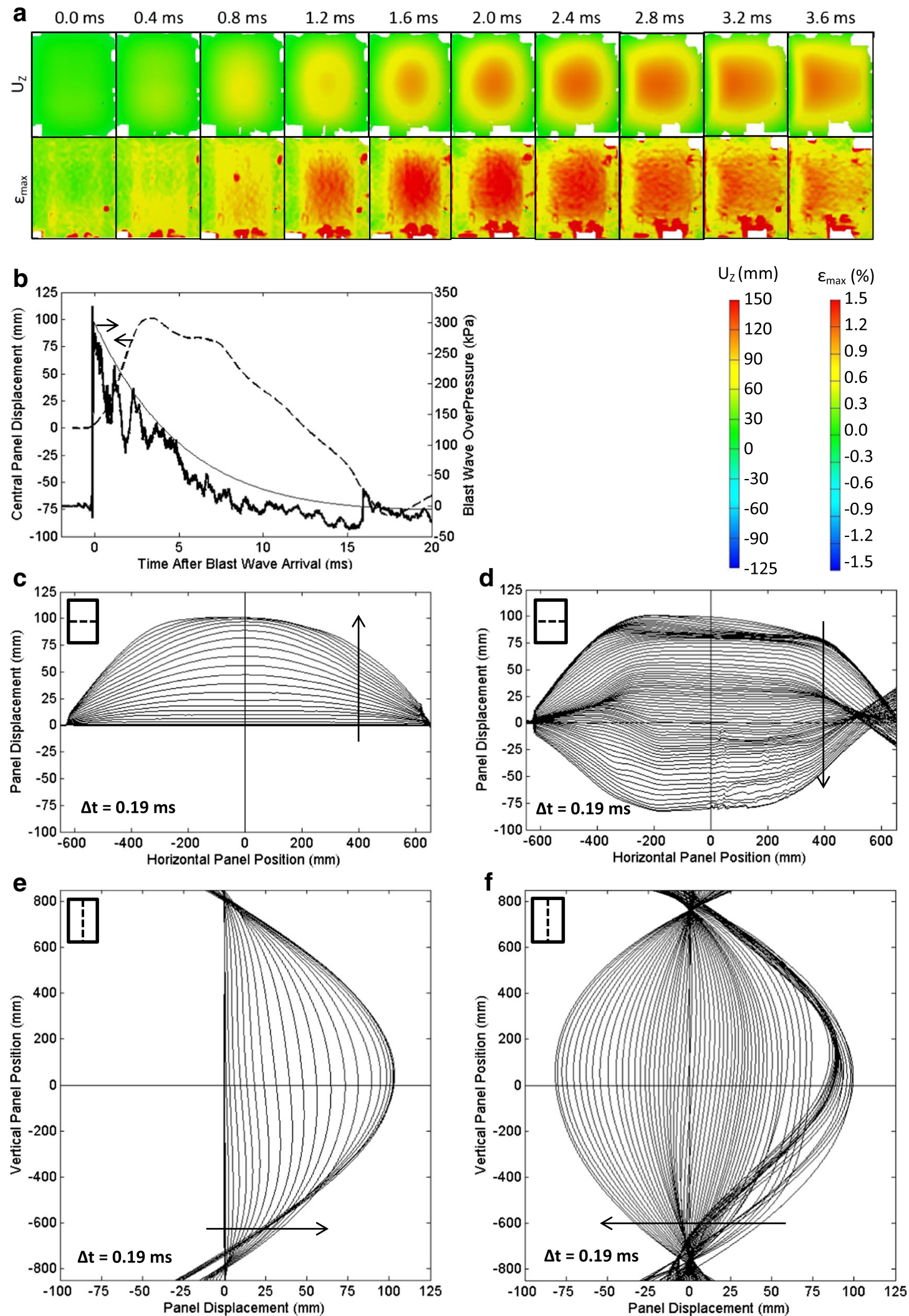

Fig. 8 Response of the single PVC core sandwich panel using DIC: (a) DIC contour plots of out of plane displacement (U $\mathrm{Z}_{\mathrm{Z}}$ ) and maximum principal strain $\left(\varepsilon_{\max }\right)$; (b) The central displacement of the sandwich panel (dashed) and the calculated and measured reflected overpressure (solid) with time; (c) The positive phase of the horizontal centre section of the panel; (d) The negative phase of the horizontal centre section of the panel; (e) The positive phase of the vertical centre section of the panel; (f) The negative phase of the vertical centre section of the panel 
a
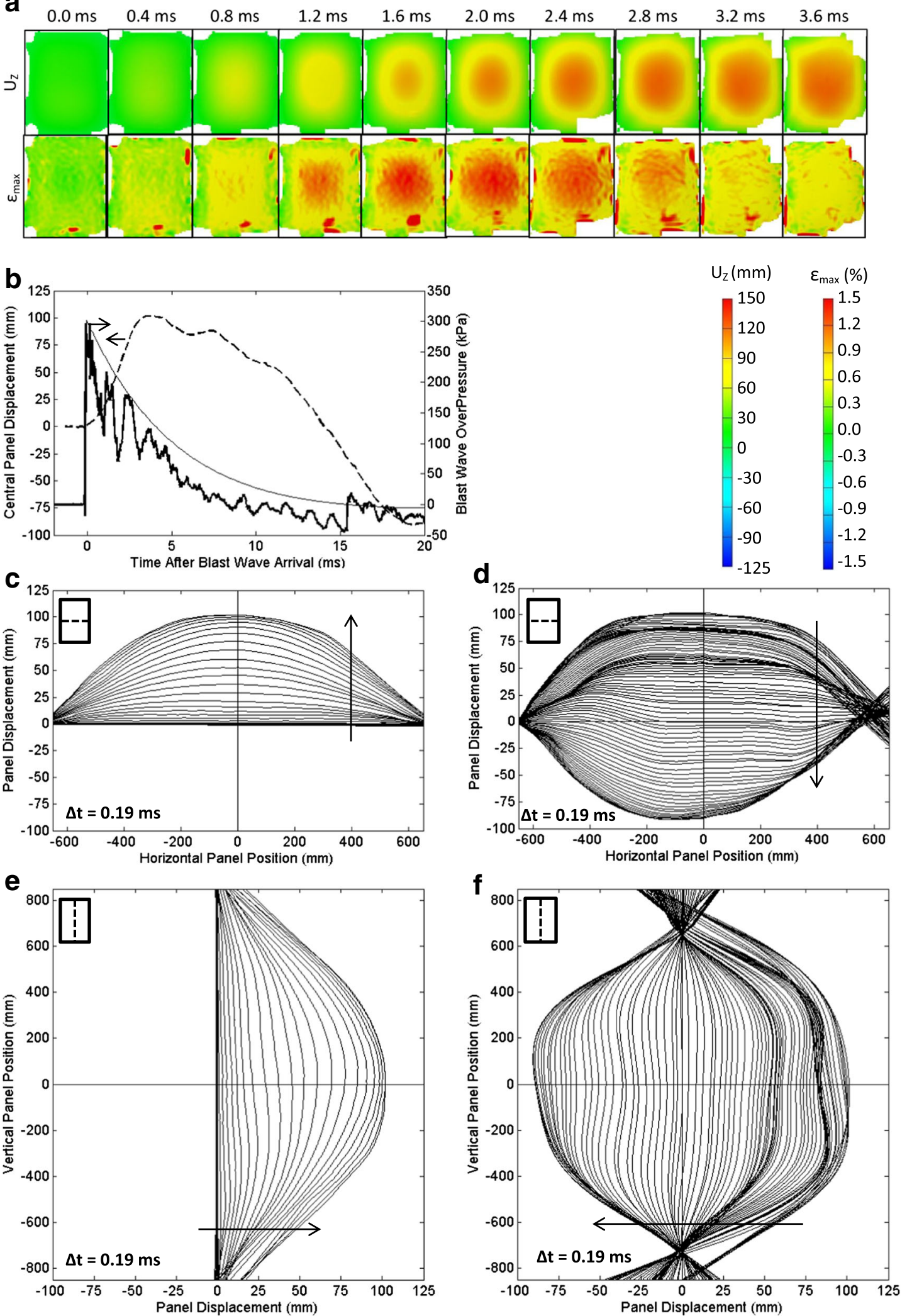

Fig. 9 Response of the single PMI core sandwich panel using DIC: (a) DIC contour plots of out of plane displacement (U $\left.\mathrm{U}_{\mathrm{Z}}\right)$ and maximum principal strain $\left(\varepsilon_{\max }\right)$; (b) The central displacement of the sandwich panel (dashed) and the calculated and measured reflected overpressure (solid) with time; (c) The positive phase of the horizontal centre section of the panel; (d) The negative phase of the horizontal centre section of the panel; (e) The positive phase of the vertical centre section of the panel; (f) The negative phase of the vertical centre section of the panel 
damage will return slower than one suffering less damage. The pull-out of the sandwich panel towards the explosive charge is caused by the high momentum of the explosive gases causing a pressure lower than 1 atmosphere at the charge location, creating a negative pressure load on the sandwich panel, as shown in Fig. 7(b). The extent of the pull-out is again dictated by damage in the sandwich panel, because if stiffness is maintained the negative deflection will be lower. Figure 7(c) provides displacement curves of the horizontal centre of the sandwich panel (highlighted by the key in the top left hand corner of the graph) for the initial positive displacement, and Fig. 7(d) shows the rebound of the sandwich panel across the same horizontal centre section. In both of these plots sharp discontinuities of gradient are present, which indicate the presence of core cracks, causing localised drops in stiffness of the panel. Also visible is a deceleration in the rebound of the sandwich panel, due to the bending wave reaching the location of the cracks, so slowing down. The sharp gradient changes cause by core cracking are also visible in the pullout phase of Fig. 7(d). A vertical central section of the SAN core sandwich panel is shown in Fig. 7(e), which has a smooth gradient across the entirety of the deflection, implying no core damage in the vertical direction. This is further validated in Fig. 7(f) which illustrates the rebound of the sandwich panel, and here deceleration is visible again, caused by the cracks across the horizontal of the sandwich panel. The deceleration shown in the section plots of the SAN core sandwich panel are also visible in the time trace of Fig. 7(b), where a second peak deflection is visible at around $8 \mathrm{~ms}$.

The DIC response of the $40 \mathrm{~mm}$ thick PVC foam core sandwich panel is illustrated in Fig. 8 and the contour plots of $U_{Z}$ and $\varepsilon_{\max }$ are shown in Fig. 8(a). The contour plots of $\varepsilon_{\max }$ between $0.0 \mathrm{~ms}$ and $0.4 \mathrm{~ms}$ indicate a high build up of strain in strips along the two vertical edges of the panel, which is caused by early cracking of the foam core resulting in local strain concentrations of the back face-sheet. Figure 8 (b) provides the central displacement of the sandwich panel and the reflected pressure profile with time and in this case the peak displacement was $103 \mathrm{~mm}$, the maximum pull-out was $83 \mathrm{~mm}$ and the positive displacement duration was $12.4 \mathrm{~ms}$. The positive deflection of the horizontal central section of the panel is provided in Fig. 8(c) with the rebound phase shown in Fig. 8(d), and again sharp discontinuities in gradient and a deceleration in the rebound indicate the presence of core damage. In this test the discontinuities are more blunt than in the SAN core and the deflections greater, implying a greater area of core cracking along the vertical edges of the panel. The vertical central section of the sandwich panel shows no damage as indicated by the positive displacement traces in Fig. 8(e) and the rebound in Fig. 8(f).
Figure 9 shows the DIC response of the $40 \mathrm{~mm}$ thick PMI foam core sandwich panel with the DIC contour plots of $U_{Z}$ and $\varepsilon_{\max }$ illustrated in Fig. 9(a). The central displacement of the panel and calculated overpressure with time are shown in Fig. 9(b), which highlight a maximum displacement and pull-out of $101 \mathrm{~mm}$ and $92 \mathrm{~mm}$ respectively and also illustrate a second area of deceleration at around $12 \mathrm{~ms}$. The positive duration of displacement is $14.1 \mathrm{~ms}$, significantly longer than in the SAN and PVC cases. Figure 9(c) illustrates the initial positive displacement of the horizontal centre of the panel and the horizontal rebound is shown in Fig. 9(d), with significant gradient discontinuities which indicate heavy core cracking. Furthermore the two periods of deceleration and the lack of displacement discontinuities in the pull-out, combined with a high pull-out displacement suggest very heavy core cracking, as the panel stiffness is greatly deteriorated. Figure 9(e) and (f) provide the positive displacement and rebound of the vertical central section respectively, and in this case cracking is implied in the vertical direction as well in the form of sharp gradient changes.

The central displacements of the three sandwich panels are collated in Fig. 10, for comparison.

\section{Graded density core}

The graded density core sandwich panel was directly compared to the single $40 \mathrm{~mm}$ thick SAN foam core sandwich panel, the results of which were presented in "Varying polymer types" section. As detailed previously the graded density sandwich panels contained a stepwise increase of foam density away from the blast side, and the DIC results of the blast test are shown in Fig. 11.

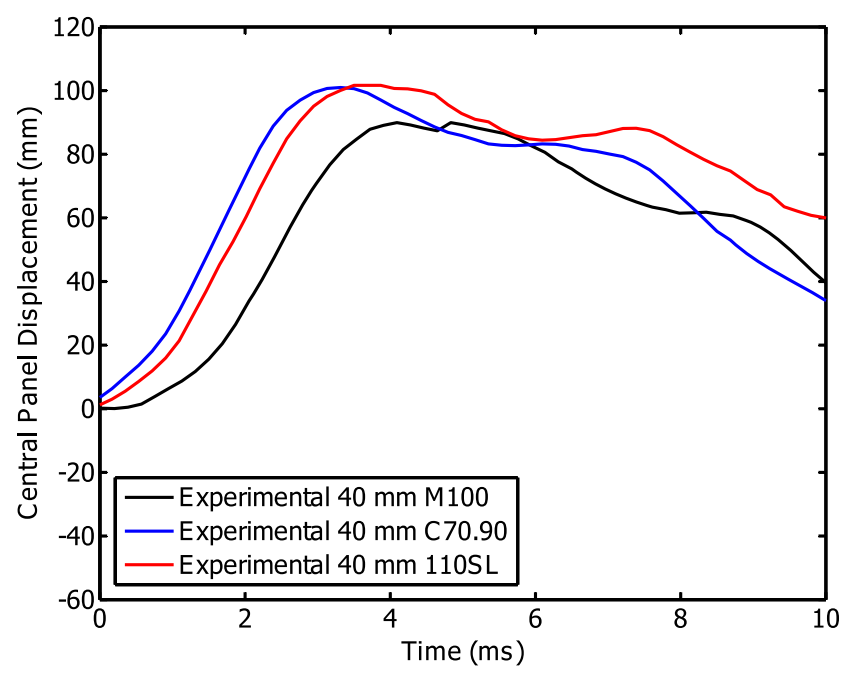

Fig. 10 Comparison of the central deflections versus time for the M100 SAN, C70.90 PVC and 110SL PMI foam core cases 

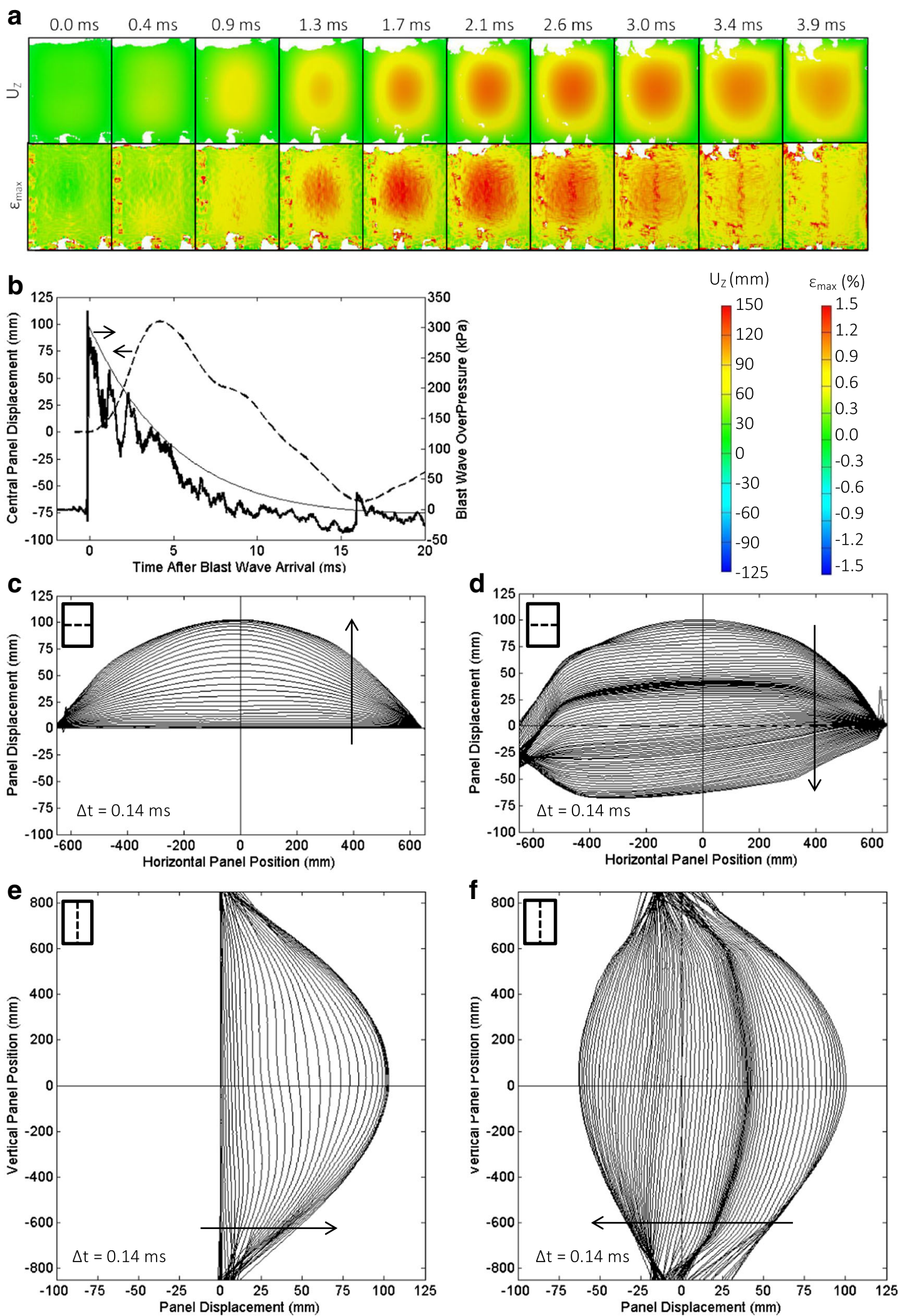

Fig. 11 Response of the graded density core sandwich panel using DIC: (a) DIC contour plots of out of plane displacement ( $\left.U_{Z}\right)$ and maximum principal strain $\left(\varepsilon_{\max }\right)$; (b) The central displacement of the sandwich panel (dashed) and the calculated and measured reflected overpressure (solid) with time; (c) The positive phase of the horizontal centre section of the panel; (d) The negative phase of the horizontal centre section of the panel; (e) The positive phase of the vertical centre section of the panel; (f) The negative phase of the vertical centre section of the panel 

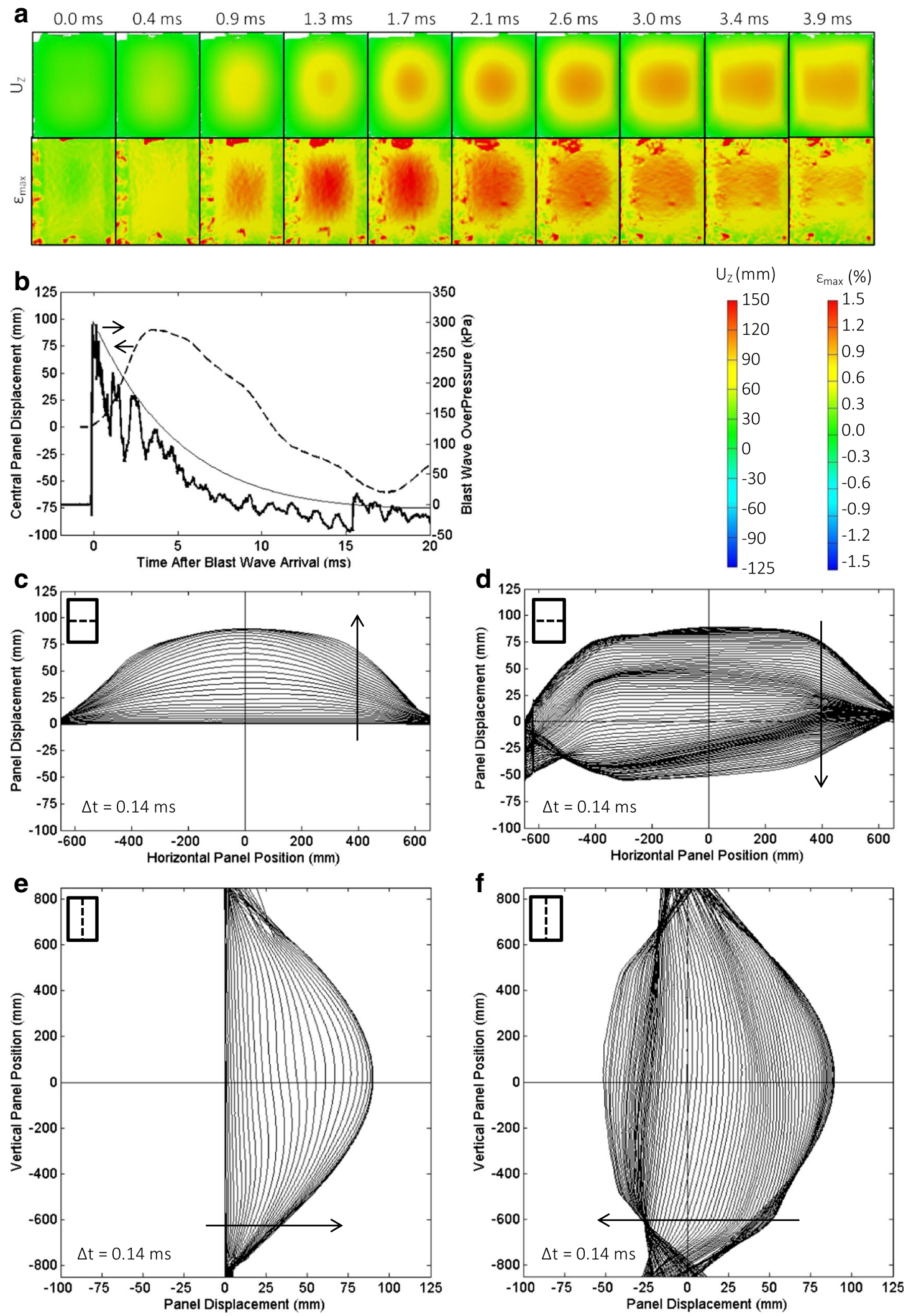

Fig. 12 Response of the PP interlayer sandwich panel using DIC: (a) DIC contour plots of out of plane displacement $\left(\mathrm{U}_{\mathrm{Z}}\right)$ and maximum principal strain $\left(\varepsilon_{\max }\right)$; (b) The central displacement of the sandwich panel (dashed) and the calculated and measured reflected overpressure (solid) with time; (c) The positive phase of the horizontal centre section of the panel; (d) The negative phase of the horizontal centre section of the panel; (e) The positive phase of the vertical centre section of the panel; (f) The negative phase of the vertical centre section of the panel 
Figure 11(a) illustrates the central displacement and calculated reflected overpressure with time, showing a maximum deflection of $103 \mathrm{~mm}$, a positive deflection duration of $11.2 \mathrm{~ms}$ and a maximum pull-out of $79 \mathrm{~mm}$. The horizontal central section of the sandwich panel during the initial positive displacement and rebound are shown in Fig. 11(c) and (d) respectively and in these plots it can be seen that core damage implied by sharp changes in gradient are minimal, and the deceleration of the rebound happens much later. Plots of the vertical central section of the graded sandwich panel are illustrated in Fig. 11(e) and (f) for the positive displacement and rebound respectively, and these plots imply no damage in the vertical direction.

\section{Polypropelene interlayer}

The final study performed in this air blast research was the incorporation of complaint PP fibre layers between the GFRP layers in the front face-sheet, in order to prevent through-thickness cracking of the front face-sheet. The DIC response of the sandwich panel to blast is shown in Fig. 12, with the contour plots of $\mathrm{U}_{\mathrm{Z}}$ and $\varepsilon_{\max }$ provided in Fig. 12(a). Figure 12(b) shows the central displacement and calculated reflected overpressure with time during the test, highlighting a maximum displacement of $92 \mathrm{~mm}$, a maximum pull-out of $65 \mathrm{~mm}$ and a positive displacement duration of $10.7 \mathrm{~ms}$. The horizontal centre section of positive deflection is illustrated in Fig. 12(c) and the rebound is shown in Fig. 12(d), with 0.14 ms between profile plots. Damage is visible in these traces in the form of gradient discontinuities and deceleration, as highlighted in previous results. Vertical centre plots are shown in Fig. 12(e) and (f) for the initial deflection and rebound respectively, and in the rebound case some slight damage is visible on the bottom of the sandwich panel, but the deceleration is much less pronounced in this case. A direct comparison of the central displacement of the compliant face-sheet panel and the $40 \mathrm{~mm}$ thick PVC foam core case is shown in Fig. 13.

\section{Post-Blast Damage Assessment}

Further to DIC during blast loading, the response of the five sandwich panels was determined using post-blast damage assessment. The clamped regions of the panels were first removed and then the actual tested section of the panel split into 16 parts, to assess the amount of debonding of the face-sheets from the core, and the amount of cracks in the core. The amount of debonding was then quantified for each foam/face-sheet boundary individually by tracking the debond, and representing this as a percentage of the section edge. The total amount of through thickness cracks were also counted, and cracking damage was quantified by finding the percentage of the section edge where there is cracking present in the foam core. The sandwich panel has been sectioned into just 16 parts, to give a purely comparitive estimate of damage suffered between the sandwich panels. The panel has been split such to allow for postblast strength assessments to be performed on the sandwich panels, similar to the research performed by Arora et al. [22].

\section{Varying polymer types}

The damage of the sectioned $40 \mathrm{~mm}$ thick SAN core sandwich panel is shown in Fig. 14, with Fig. 14(a) providing the percentages of debonding or cracking on each section edge. The number on each section is the average amount of damage for that section, taken as the average of the four bounding edges. The left hand diagram in Fig. 14(a) shows debonding between the front (blast side) face-sheet and the core; the central image shows core cracking, and the right hand image shows debonding between the back face-sheet and core. Figure 14(b) shows a photograph of the front facesheet after blast, which contains one compressive crack, and Fig. 14(c) provides an example of a section edge, with damage highlighted in red. Figure 14(d) is a photograph of the vertical right section edges, and Fig. 14(e) is a photograph of the horizontal bottom edges. Figure 15 illustrates the damage observed in the single PVC foam core sandwich panel, and the percentage damage schematic is shown in Fig. 15(a). Figure 15(b) provides a photograph of the front face-sheet and Fig. 15(c) shows and example section edge, both with damage highlighted in red. Figure 15(d) and (e) show photographs of the sectioned vertical and horizontal section edges respectively. In the case of the single density PMI foam core sandwich panel, the damage to the foam

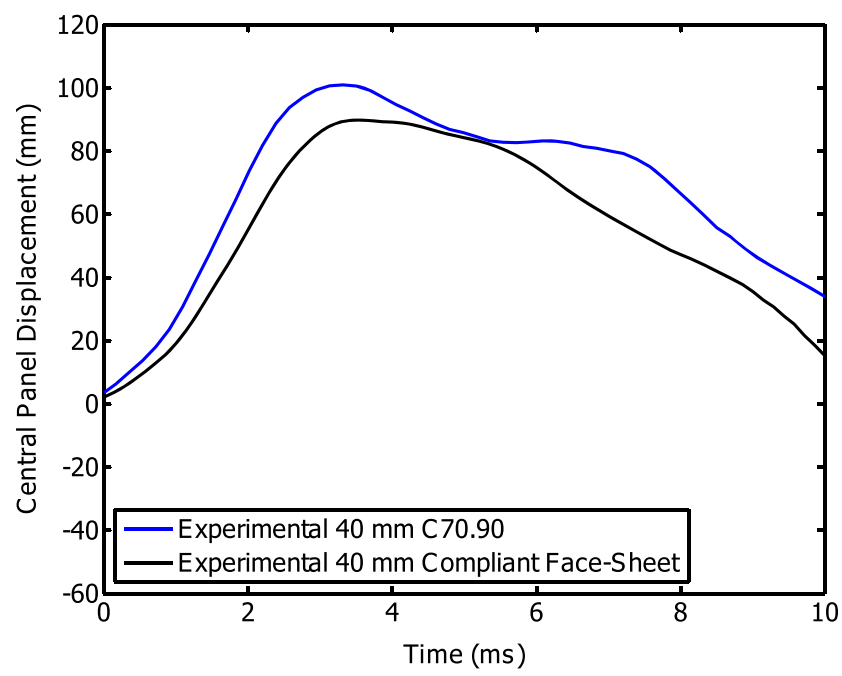

Fig. 13 Comparison of the central deflections versus time for the PVC C70.90 core and the compliant face-sheet cases 
Fig. 14 Post-blast damage assessment of the single $40 \mathrm{~mm}$ thick SAN foam core sandwich panel. (a) Schematic of the front face-sheet, foam core and back face-sheet with the amount of debonding and cracks; (b) Photograph of the front face-sheet after blast, with the compressive crack shown in red; (c) photograph of an example of a section edge, with damage highlighted in red; (d) Photograph of the long edges of the sandwich panel; (e) photograph of the short edge of the sandwich panel

\section{a}

Debonding between front

Damage

face-sheet and SAN core

\begin{tabular}{|l|l|l|l|}
\hline $0 \%$ & $0 \%$ & $0 \%$ & $18 \%$ \\
\hline $7 \%$ & $0 \%$ & $15 \%$ & $78 \%$ \\
\hline $27 \%$ & $0 \%$ & $0 \%$ & $36 \%$ \\
\hline $0 \%$ & $0 \%$ & $6 \%$ & $18 \%$ \\
\hline
\end{tabular}

Total debond = 13\%

b

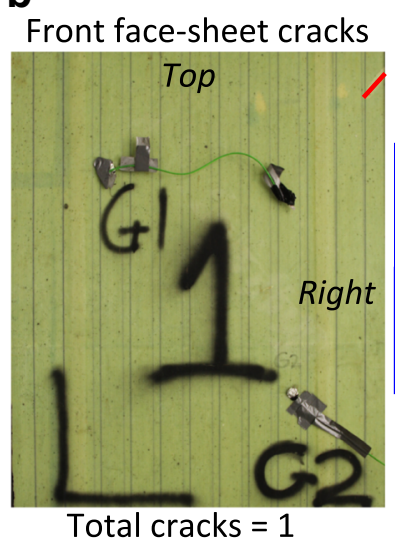

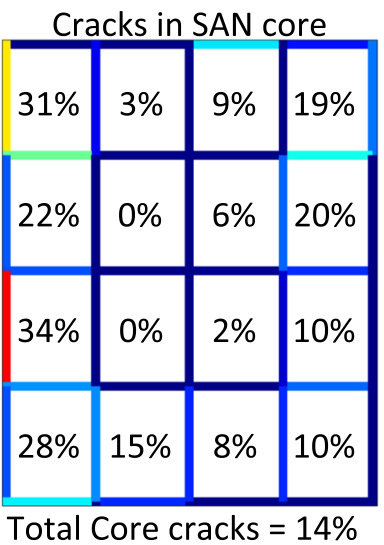

Total through-thickness

cracks $=34$

Debonding between back

face-sheet and SAN core

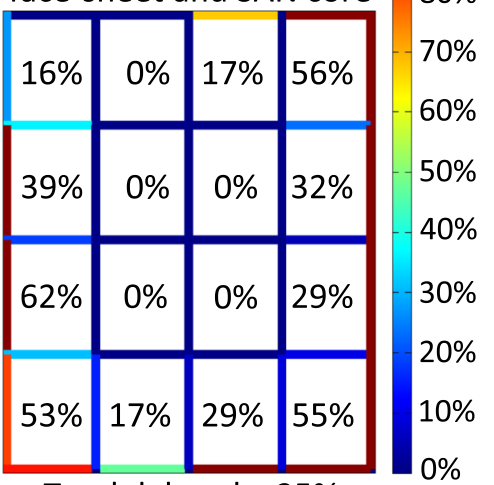

Total debond $=25 \%$

C

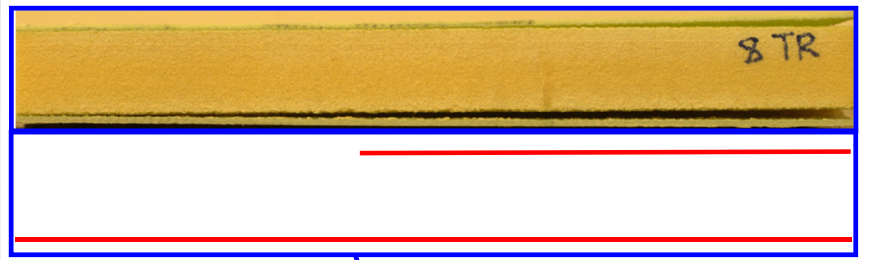

Total cracks $=1$
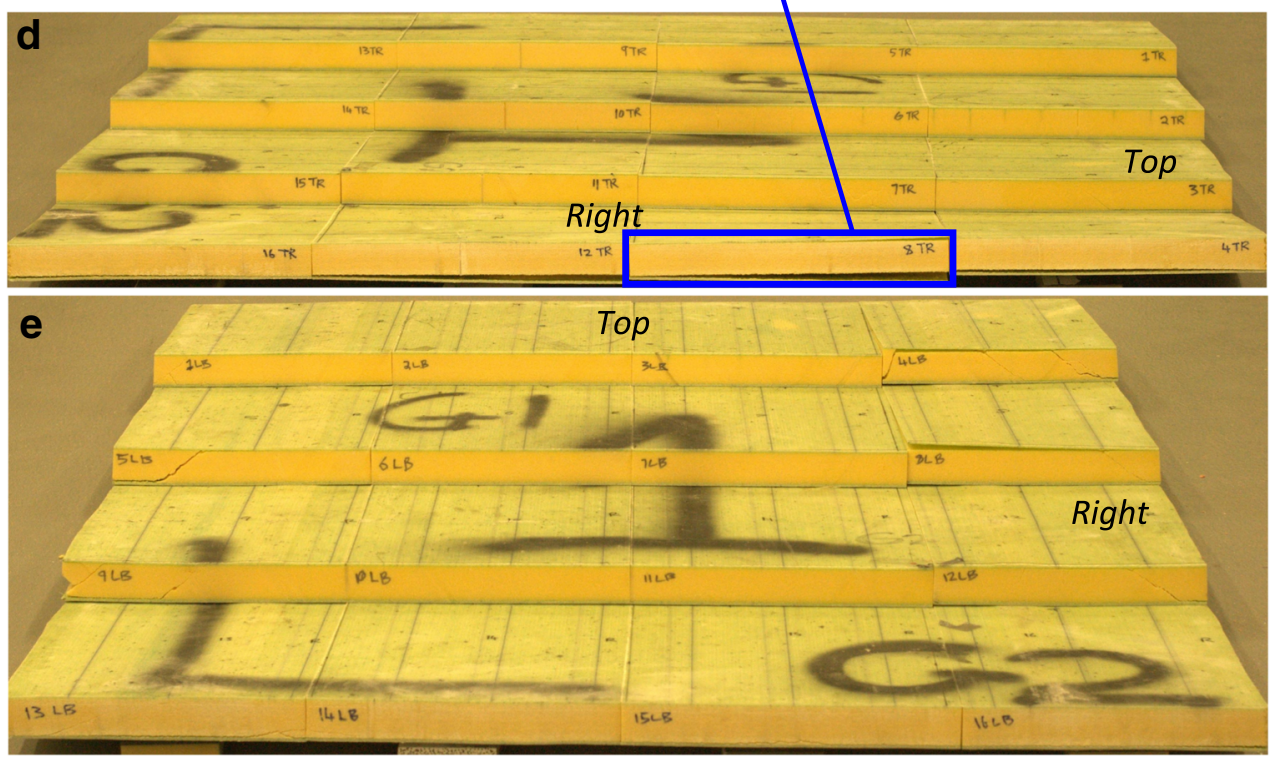

was too significant to section the panel, however Fig. 16 provides an indication of the amount of damage in the sandwich panel. In order to quantify damage in this case, the amount of complete debond between each face-sheet and the core was physically measured, which are shown in grey on the central and right hand images in Fig. 16. This was 
Fig. 15 Post-blast damage assessment of the single $40 \mathrm{~mm}$ thick PVC foam core sandwich panel. (a) Schematic of the front face-sheet, foam core and back face-sheet with the amount of debonding and cracks; (b) Photograph of the front face-sheet after blast, with compressive cracks shown in red; (c) photograph of an example of a section edge, with damage highlighted in red; (d) Photograph of the long edges of the sandwich panel; (e) photograph of the short edge of the sandwich panel

\section{a}

Debonding between front face-sheet and PVC core

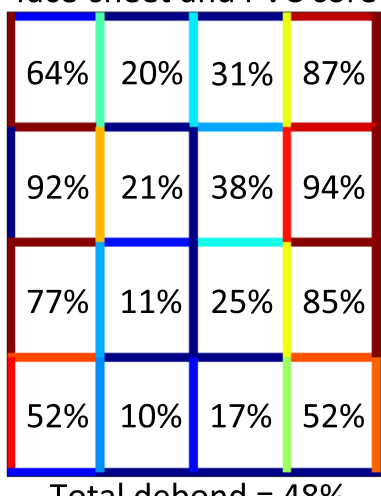

Total debond $=48 \%$

b
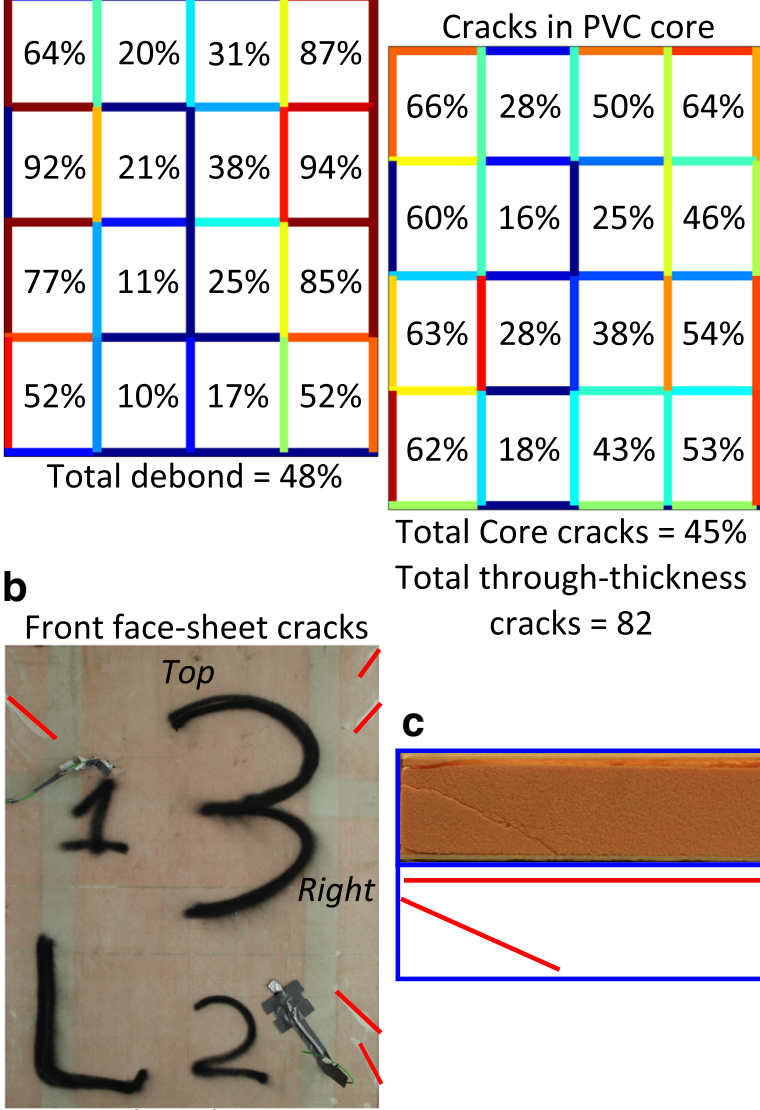

Debonding between back face-sheet and PVC core

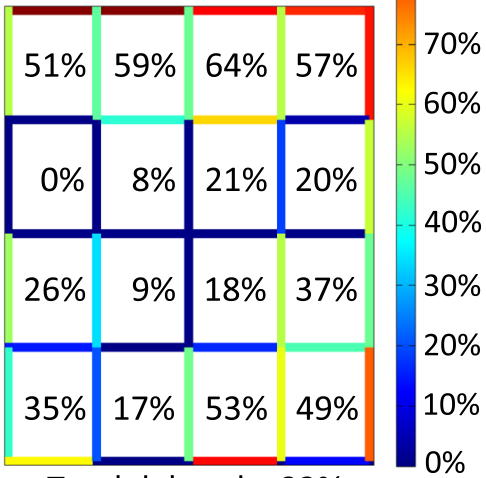

Total through-thickness cracks $=82$

Total debond $=33 \%$

C

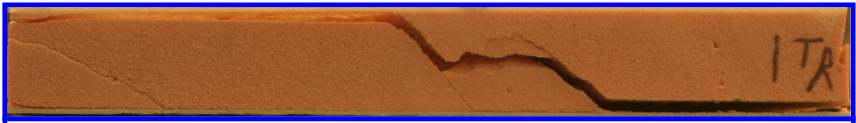

Total cracks $=5$
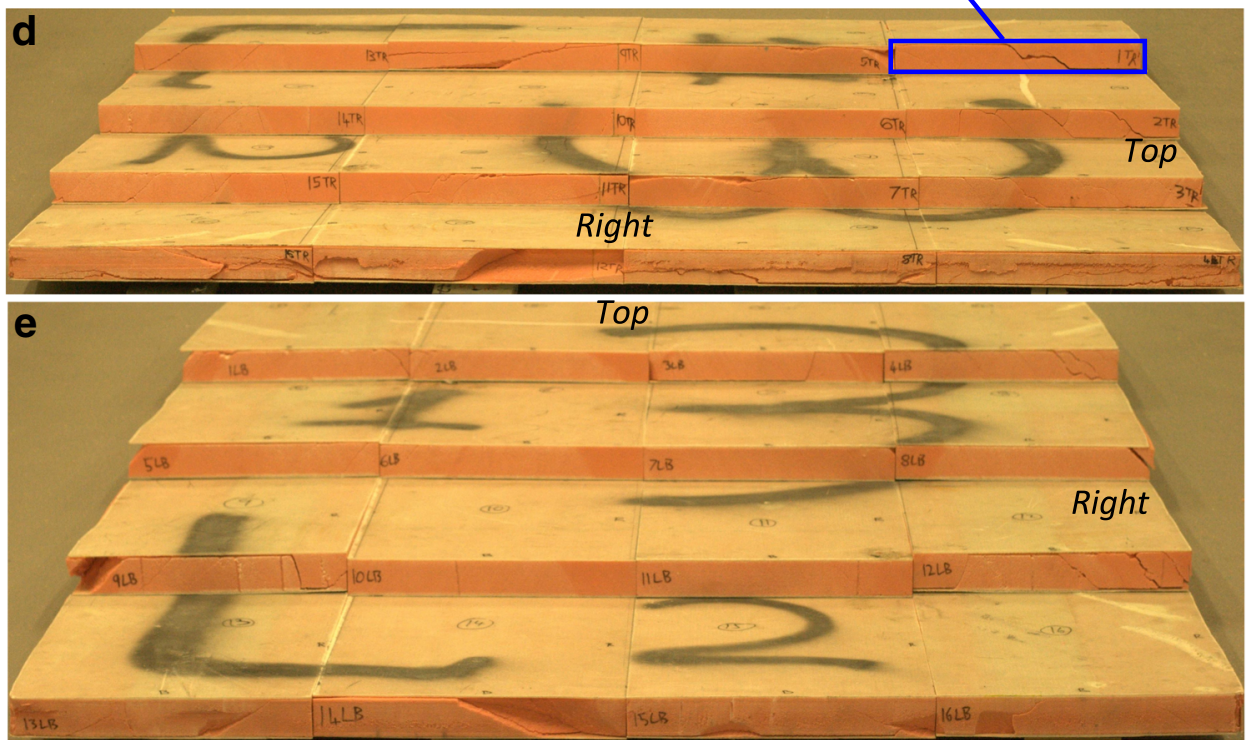

completed by removing loose foam from the panel and measureing, with a steel rule, the depth where there is no contact between the core and the face-sheet. In these zones there is also very heavy core cracking, and it is expected that core cracking continues in the sections which are not completely debonded. 


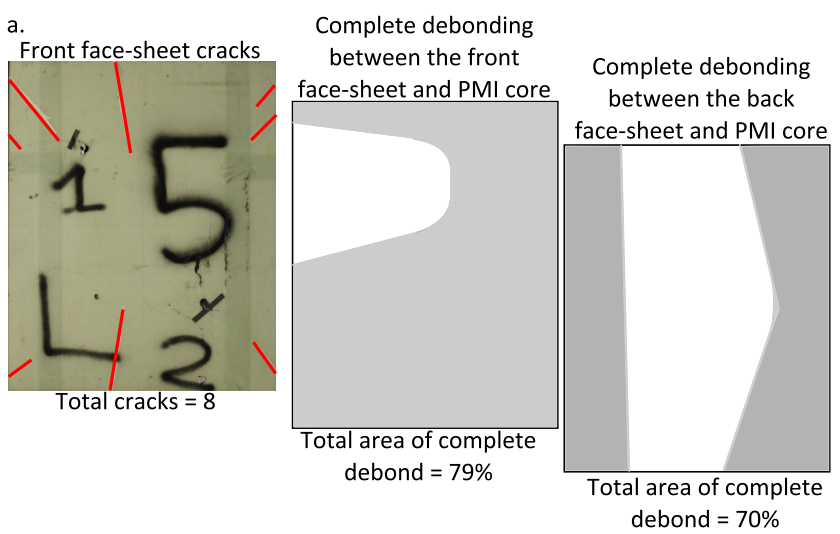

Fig. 16 Post-blast damage assessment of the PMI core sandwich panel, with compressive cracks in the front face-sheet shown on the left, the complete debonding area of the front face-sheet and the core shown in the centre, and the complete debond area between the back face-sheet and the core shown on the right

\section{Graded density}

The damage present in the post-blast sectioning of the graded density sandwich panel is shown in Fig. 17, with the schematic of the face-sheets and the damage in the foam core shown in Fig. 17(a). The number of cracks in each foam layer were counted, and then the cracks which propagate through the whole thickness were counted, resulting in the 30 cracks. The percentage of core cracks shown in the central image of Fig. 17(a) include cracking through all three layers, as well as debonding between the foam layers. Figure 17(b) shows the front face-sheet of the graded core sandwich panel, with no core cracks present, and Fig. 17(c) shows an example of a section edge, with damage highlighted in red. Figure 17(d) shows a photograph of the vertical edge of the graded sandwich panel, and Fig. 17(e) shows the horizontal edge.

\section{Polypropelene interlayer}

Figure 18 illustrates the damage of the sectioned polypropelene interlayer sandwich panel and Fig. 18(a) provides a schematic of the damage, showing debonding and core cracks. Figure 18(b) illustrates the front facesheet after blast, with no compressive cracks present, and Fig. 18(c) shows an example of a section edge with damage shown in red. The photographs of the vertical edges and the horizontal edges are shown in Fig. 18(d) and (e) respectively.

\section{Discussion}

The first comparative study performed in this research was of three different polymeric foam core types: SAN;
PVC; and PMI in sandwich panels with GFRP face-sheets. Then a comparison of a stepwise graded density SAN foam core to the single density SAN foam core from the polymer type comparison was made, and the final study was a comparison of a PVC foam core sandwich panel with polypropylene plies between the GFRP plies in the front face to the PVC foam core sandwich panel from the polymer type comparison. The important findings from the DIC results and the post-blast sectioning of the five sandwich panels are shown in Tables 5 and 6 respectively.

The foam polymer type comparison showed that the SAN foam deflected the least during blast loading, and also suffered significantly less damage than the PVC and PMI cores. The lower deflection and pull-out from the SAN core are a result of fewer shear cracks in the core, meaning that the bending stiffness is retained. The maximum displacement of the PVC and PMI cores is very similar, but the pull-out of the PMI core is significantly more than the PVC case, due to cracking occurring near to the maximum out of plane displacement, so not resulting in a large increase of deflection in the PMI case, but then reducing the bending stiffness for the rebound phase of the deflection. The damage in all three polymer comparison panels took place around the edges of the panel, with very little core cracking and debonding in the centre. Furthermore the majority of debonding was present between the back facesheet and the core. The front face-sheet cracking was much less prominent on the SAN core sandwich panel, due to less deflection meaning less compressive strain on the front face-sheet. In all three polymer comparison cases the front face sheet cracks emanated from bolt locations, due to the high stress concentrations. The PMI core was selected due to its superior stiffness and strength, both in quasi-static and dynamic loading, making it ideal for structural components. However, as indicated by Table 1, the strain to failure of PMI is much less than that of PVC and SAN, explaining the much higher damage suffered in this case. The greater damage suffered by the PVC core is, in turn, caused by the lower strain to failure of this material compared to the SAN equivalent. Figure 10 shows a comparison of the central deflections of the three sandwich panels with different foam polymer cores, and it can be seen that the SAN panel reaches maximum deflection slower than the PMI and PVC cases, due to a greater retained stiffness with less damage. The PMI case reaches maximum deflection slower than the PVC case due to it having a greater stiffness before fracture, so initially resisting deflection more. Table 5 provides botht he impulse provided to each test panel by the explosion, and the positive displacement time of the deflection. It can be seen that for the M100 case the impulse is significantly higher than in the PVC and PMI cases, but that the positive displacement time is about the same as the PVC 
Fig. 17 Post-blast damage assessment of the $30 \mathrm{~mm}$ thick graded SAN foam core sandwich panel. (a) Schematic of the front face-sheet, foam core and back face-sheet with the amount of debonding and cracks; (b) Photograph of the front facesheet after blast; (c) photograph of an example of a section edge, with damage highlighted in red; (d) Photograph of the long edges of the sandwich panel; (e) photograph of the short edge of the sandwich panel a

Debonding between front

face-sheet and graded core

\begin{tabular}{|r|r|r|r|}
\hline $15 \%$ & $13 \%$ & $2 \%$ & $29 \%$ \\
\hline $17 \%$ & $0 \%$ & $0 \%$ & $14 \%$ \\
\hline $32 \%$ & $2 \%$ & $0 \%$ & $2 \%$ \\
\hline $7 \%$ & $11 \%$ & $6 \%$ & $4 \%$ \\
\hline
\end{tabular}

b

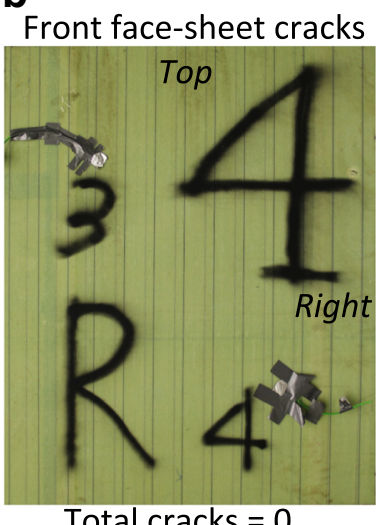

\begin{tabular}{|c|c|c|c|}
\hline \multicolumn{4}{|c|}{ Cracks in graded core } \\
\hline $18 \%$ & $7 \%$ & $7 \%$ & $8 \%$ \\
\hline $7 \%$ & $0 \%$ & $0 \%$ & $4 \%$ \\
\hline $15 \%$ & $4 \%$ & $0 \%$ & $5 \%$ \\
\hline $9 \%$ & $9 \%$ & $2 \%$ & $11 \%$ \\
\hline
\end{tabular}

Debonding between back

Damage $100 \%$

$90 \%$ face-sheet and graded core $80 \%$

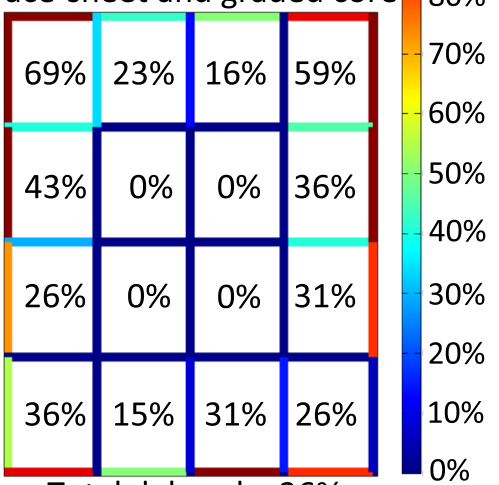

Total through-thickness cracks $=30$

Total debond $=26 \%$

C

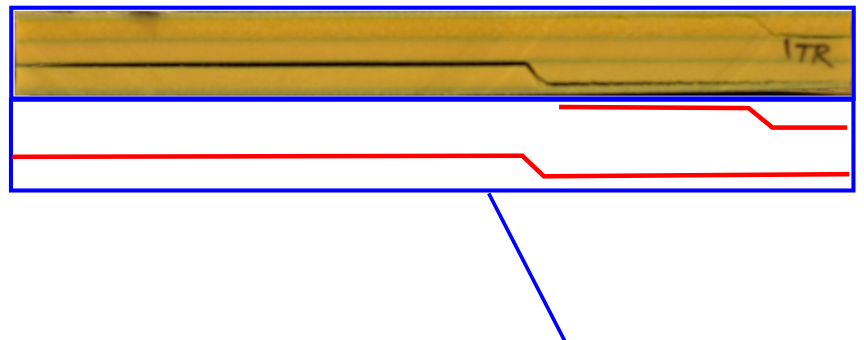

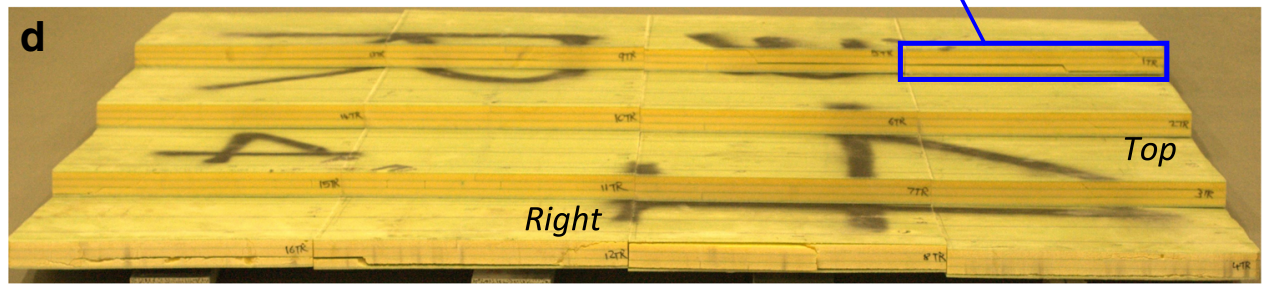

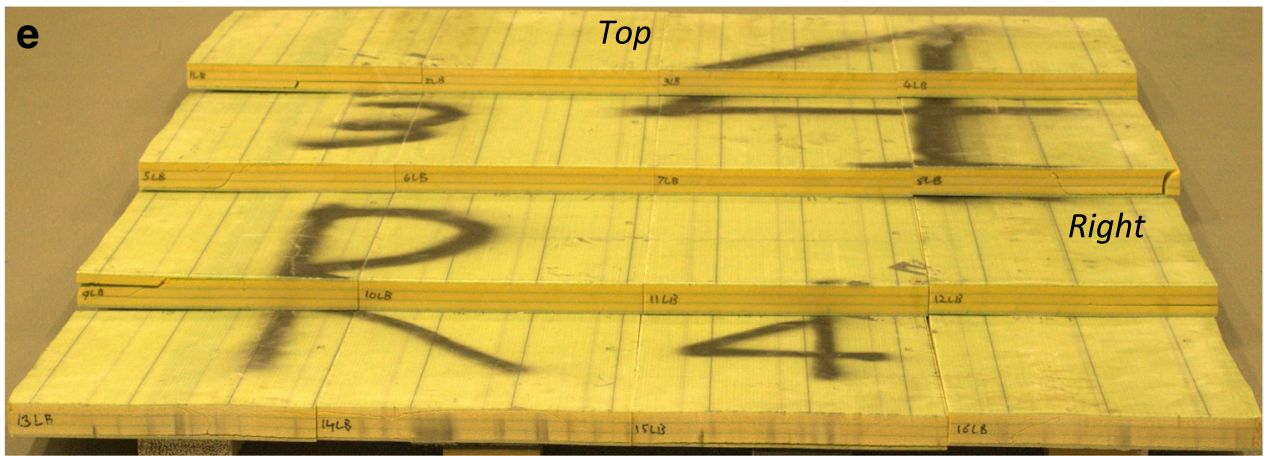

case, and much lower than the PMI case. This shows that great stiffness is retained in the sandwich panel.

The results of using a graded density core in the sandwich panel are to prevent through thickness cracking, and reduce the maximum out of plane displacement. The graded density sandwich panel had a $30 \mathrm{~mm}$ foam core, and was used in a direct comparison to a single density $40 \mathrm{~mm}$ thick SAN core. Due to an increased second moment of area the 
Fig. 18 Post-blast damage assessment of the compliant front face-sheet, $40 \mathrm{~mm}$ thick PVC foam core sandwich panel. (a) Schematic of the front face-sheet, foam core and back face-sheet with the amount of debonding and cracks; (b) Photograph of the front facesheet after blast; (c) photograph of an example of a section edge, with damage highlighted in red; (d) Photograph of the long edges of the sandwich panel; (e) photograph of the short edge of the sandwich panel a

Debonding between front face-sheet and PVC core

\begin{tabular}{|r|r|r|r|}
\hline $19 \%$ & $19 \%$ & $17 \%$ & $16 \%$ \\
\hline $31 \%$ & $3 \%$ & $13 \%$ & $22 \%$ \\
\hline $25 \%$ & $3 \%$ & $6 \%$ & $13 \%$ \\
\hline $4 \%$ & $4 \%$ & $7 \%$ & $2 \%$ \\
\hline
\end{tabular}

Total debond $=13 \%$

b

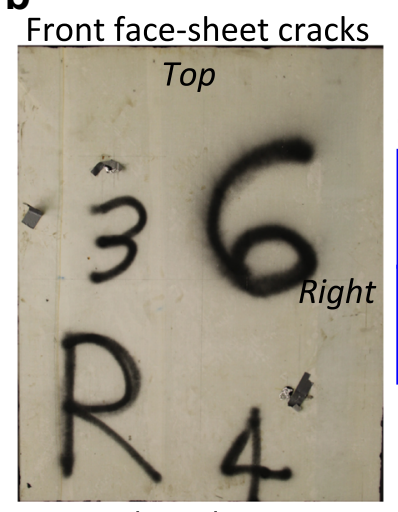

\begin{tabular}{|l|l|l|l|}
\multicolumn{3}{|c|}{ Cracks in PVC core } \\
\hline $55 \%$ & $37 \%$ & $47 \%$ & $62 \%$ \\
\hline $52 \%$ & $35 \%$ & $31 \%$ & $59 \%$ \\
\hline $30 \%$ & $23 \%$ & $34 \%$ & $49 \%$ \\
\hline $51 \%$ & $39 \%$ & $56 \%$ & $44 \%$ \\
\hline
\end{tabular}

Total Core cracks $=44 \%$

Total through-thickness

cracks $=110$

C
Damage

$100 \%$

Debonding between back $90 \%$

face-sheet and PVC core

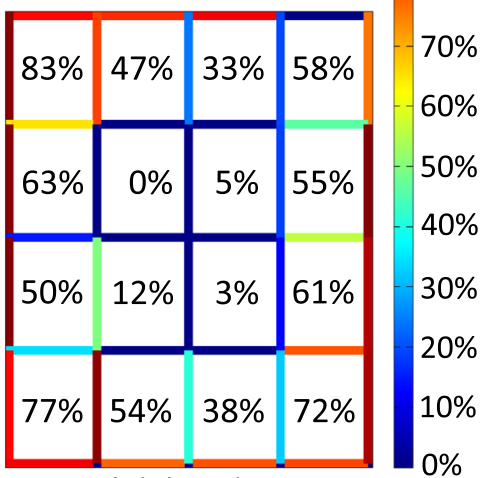

Total debond $=44 \%$

$80 \%$

$70 \%$

$60 \%$

$50 \%$

$40 \%$

$0 \%$

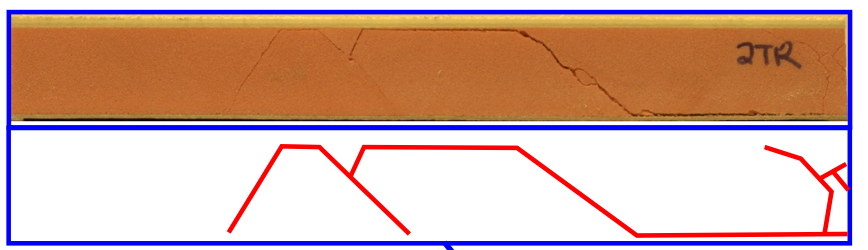

Total cracks $=0$
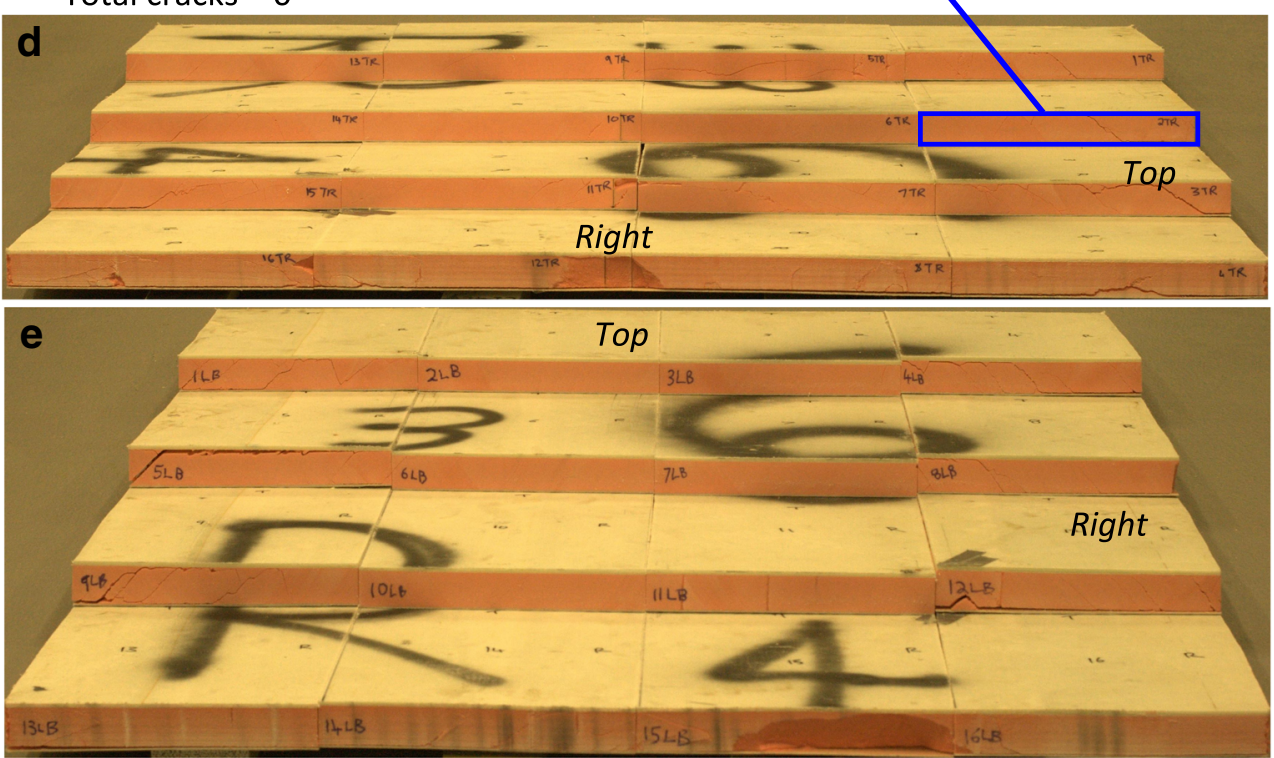

$40 \mathrm{~mm}$ core would be expected to possess a greater bending stiffness, and in research performed by Arora, Hooper and Dear [2] a $40 \mathrm{~mm}$ single density SAN foam core was compared to a $30 \mathrm{~mm}$ single density $\mathrm{SAN}$ core. The SAN foams were the same, as well as the explosive loading conditions, and the stand-off distance from the $30 \mathrm{~kg} \mathrm{C} 4$ charge was determined such that the sandwich panel response remained elastic. In this research it was concluded that the increase in 
Table 5 Peak pressure and impulse, and DIC results summary.

\begin{tabular}{lllll}
\hline Name & $\begin{array}{l}\text { Reflected blast } \\
\text { impulse (kPa.ms) }\end{array}$ & $\begin{array}{l}\text { Maximum deflection } \\
(\mathrm{mm})\end{array}$ & $\begin{array}{l}\text { Maximum } \\
\text { pull-out (mm) }\end{array}$ & $\begin{array}{l}\text { Positive displacement } \\
\text { time (ms) }\end{array}$ \\
\hline SAN Core & 962 & 89 & 45 & 12.8 \\
PVC Core & 817 & 103 & 83 & 12.4 \\
PMI Core & 732 & 101 & 92 & 14.1 \\
Graded Core & 817 & 103 & 79 & 11.2 \\
Polypropelene interlayer & 732 & 92 & 65 & 10.7 \\
\hline
\end{tabular}

out of plane deflection from decreasing the panel thickness from $40 \mathrm{~mm}$ to $30 \mathrm{~mm}$ was $24 \%$ (from $63 \mathrm{~mm}$ to $78 \mathrm{~mm}$ ). If it assumed that a similar increase in deflection would be present in the inelastic case presented here, a peak deflection of $110 \mathrm{~mm}$ is implied for the graded density sandwich panel, whereas the deflection actually measured was $103 \mathrm{~mm}$, as shown in Table 5. This result indicates that peak deflection of the sandwich panel can be reduced by using a graded density foam core. Furthermore, the results of Fig. 7(c) and (d) show that the horizontal contour shape of the graded sandwich panel is much smoother than the other sandwich panels. This is due to less cracking in the higher density core than at the back, and is due to the majority of the crack density being at the front in the lower density foams. In marine applications the importance of back face-sheet integrity is high, so this is a positive result for this application. Gardner, Wang and Shukla [5] performed blast testing of graded density cores using blast waves with high peak pressures, which caused progressive crushing of the lower density foam layers, thus attenuating the blast wave energy. In the blast tests performed in this research, the peak blast pressures are too low to cause crushing damage in the foam cores, and all of the damage is caused by the blast wave impulse resulting in core cracking due to bending of the sandwich panel. In the post-blast sectioning of the graded density sandwich panel it was found that having interfaces between the three foam layers caused cracks propagating through the foams core to be arrested at these boundaries, so reduce the amount of through thickness cracks. The number of cracks observed was comparable to the $40 \mathrm{~mm}$ thick SAN sandwich panel, but more cracks would be expected due to the reduction in thickness. This same effect could be achieved by using layers of the same foam density, but alongside the attenuation in higher peak pressure blast, and the reduced deflection with the graded density core, the conclusion is that blast resistance is increased with the use of a graded density foam core in the sandwich panel.

The results of the comparative study into using compliant PP plies within the front face-sheet GFRP plies of the sandwich panel imply that front face-sheet cracking can be prevented with this method. As shown in Table 6 no front face-sheet cracks were observed in this sandwich panel, despite significant core cracking being observed in the post blast sectioning. The amount of core cracking was similar to that observed in the PVC core sandwich panel, implying that the introduction of the PP plies in the front face-sheet simply acted to prevent cracking, which is an important conclusion for the consideration of the use of sandwich composites in marine applications. The out of plane deflection and pullout of the compliant front face-sheet sandwich panel was less than the single PVC core case, as shown in Fig. 13, due to the greater thickness of the front face-sheet, increasing the bending stiffness of the panel. This also caused the sandwich panel to return more quickly, so have a lower positive displacement time period.

The deceleration illustrated in the rebounds of all 5 sandwich panels were visible due to the use of high speed cameras with frame rates over $2000 \mathrm{~s}^{-1}$, as at this speed only one frame is captured over the deceleration period. Also by using a minimum camera frame rate of $5400 \mathrm{~s}^{-1}$, three or four frames are captured at maximum deflection and pull-out, implying that the measured maximum out of plane displacement and pull-out are accurate. By speckling the inside front of the test cubicle before blast testing, it was possible to align the cameras so that this was in shot and remove the out of plane displacement of the cubicle
Table 6 Summary of damage from post-blast sectioning.

\begin{tabular}{llll}
\hline Name & $\begin{array}{l}\text { Number of front } \\
\text { face-sheet cracks }\end{array}$ & $\begin{array}{l}\text { Number of through thickness } \\
\text { core cracks }\end{array}$ & $\begin{array}{l}\text { Total amount of } \\
\text { debonding }(\%)\end{array}$ \\
\hline SAN Core & 1 & 34 & 19 \\
PVC Core & 5 & 82 & 41 \\
PMI Core & 8 & $>200$ & $>75$ \\
Graded Core & 0 & 30 & 18 \\
Polypropelene Interlayer & 0 & 110 & 29 \\
\hline
\end{tabular}


front from the DIC calculations. Twisting is still present in the cubicle front, and this is visible from the displacement present in the horizontal sections on the DIC contour plots, but this is greatly reduced by removing the movement of the rigid I-beam in the centre of the cubicle. The consistency of the blast loading has also been ensured by comparing the static overpressures measured during each test, and checking these against calculated values.

\section{Conclusion}

The following bullets summarise the conclusions for the full=scale explosive testing of sandwich panels researched in this paper:

- By using high speed cameras with frame rates greater than $2000 \mathrm{~s}^{-1}$ the maximum out of plane displacement and pull-out can be accurately measured, and the deceleration of the sandwich panel rebound caused by core cracking is visible.

- The use of speckles on a rigid section of the test cubicle allows rigid body motions of the test structure during the test to be removed in the DIC processing, so that the actual deflection of the sandwich panel can be determined. There is still twisting present in the cubicle front, which can be seen in the edges of some of the contour plots taken from DIC, and these could be reduced by speckling all of the inside sections of the cubicle front, rather than just the centre section.

- In a comparison of SAN, PVC and PMI foam cores of equal density and thickness, it was found that all cores offered good resistance to blast at this charge size and stand-off distance, but that SAN offers the best blast resistance with minimal out of plane displacement and pull-out, and suffers the least damage from blast testing. The PMI core offers the best stiffness and strength, so if used within the elastic limit would offer the most suitable properties. The overriding factor for the foam in blast response is the strain to failure, as the stiffness of the foam is very low in comparison to the face-sheets.

- The use of a stepwise graded density foam core reduces the amount of core damage due to interfaces inhibiting crack propagation through the core, thus reducing the amount of out of plane displacement and pull-out of the sandwich panel. Furthermore, the majority of core cracking takes place in the lower density foam layers, allowing for a smoother rear face-sheet deformation.

- By placing compliant PP plies between the GFRP plies in the front face-sheet, cracking of the front face-sheet is prevented. This happens despite the same amount of core damage present in the compliant face-sheet panel as in the single density PVC core sandwich panel to which the comparison was made. This conclusion is important for marine applications due to the prevention of front face-sheet cracking retaining the structural integrity of the sandwich panel.

Further blast testing will also be performed in underwater conditions, in order to investigate the different responses with high peak pressures in the blast wave, which will cause core crushing in the sandwich panel. This will be of particular interest in the graded density core sandwich panel, where it is expected that stepwise core crushing will take place in underwater blast scenarios, thus attenuating the blast wave. The experimental findings that are presented in this paper on full-scale explosive blast evaluation of different composite sandwich structures have provided valuable fullscale assessments for designers and engineers employing lightweight composite marine superstructures of the future.

Acknowledgments Greatly appreciated is the support from Dr Yapa Rajapakse of the Office of Naval Research (ONR Solid Mechanics Program), for supporting Dr Mark Kelly and Dr Hari Arora in their PhDs(N00014-08-1-1151 \& N00014-12-1-0403) and EPSRC TARFLCV (Grant Ref: EP/I038616/1), Arup Resilience, Security and Risk with EPSRC for supporting Dr Paolo Del Linz during his PhD, MoD for supporting Dr Alex Worley, AVIC Beijing Institute of Aeronautical Materials (BIAM), through the AVIC Centre for Material Characterisation, Processing and Modelling, for supporting Dr Hari Arora as a postdoctoral researcher and AVIC the First Aircraft Institute (FAI), through the AVIC Centre for Structural Design and Manufacture, for supporting Dr Michael Kaye as a postdoctoral researcher. Also much appreciated are GOM UK and LaVision for their ongoing support, Slow Mo Camera Hire for the use of high speed cameras and DNV GL and CPNI for their assistance with blast testing.

\section{References}

1. Arora H, Hooper P, Dear J (2011) Dynamic response of full-scale sandwich composite structures subject to airblast loading. Compos A Appl Sci Manuf 42(11):1651. doi:10.1016/j.compositesa.2011.07.018. http://linkinghub. elsevier.com/retrieve/pii/S1359835X11002247

2. Arora H, Hooper PA, Dear JP (2011) The Effects of Air and Underwater Blast on Composite Sandwich Panels and Tubular Laminate Structures. Exp Mech 52(1):59. doi:10.1007/s11340-011-9506-z. http://www.springerlink.com/ index/10.1007/s11340-011-9506-z

3. Latourte F, Grégoire D, Zenkert D, Wei X, Espinosa HD (2011) Failure mechanisms in composite panels subjected to underwater impulsive loads. J Mech Phys Solids 59(8):1623. doi:10.1016/j.jmps.2011.04.013. http://linkinghub.elsevier.com/ retrieve/pii/S0022509611000834

4. Zhu F, Wang Z, Lu G, Zhao L (2009) Mater Des 30(1):91. doi:10.1016/j.matdes.2008.04.027. http://linkinghub. elsevier.com/retrieve/pii/S0261306908001192

5. Gardner N, Wang E, Shukla A (2012) Performance of functionally graded sandwich composite beams under shock wave loading. Compos Struct 94(5):1755. doi:10.1016/j.compstruct.2011.12.006. http://linkinghub.elsevier. com/retrieve/pii/S0263822311004740 
6. Gupta N, Gupta SK, Mueller BJ (2008) Analysis of a functionally graded particulate composite undersexural loading conditions. Mater Sci Eng A 485(1-2):439. doi:10.1016/j.msea.2007.08.020. http://linkinghub.elsevier.com/retrieve/pii/S0921509307015389

7. Hoo Fatt MS, Palla L (2009) Analytical Modeling of Composite Sandwich Panels under Blast Loads. J Sandw Struct Mater 11(4):357. doi:10.1177/1099636209104515. http://jsm.sagepub. com/cgi/doi/10.1177/1099636209104515

8. Andrews E, Moussa N (2009) Failure mode maps for composite sandwich panels subjected to air blast loading. Int J Impact Eng 36(3):418. doi:10.1016/j.ijimpeng.2008.08.005. http://linkinghub. elsevier.com/retrieve/pii/S0734743X08002194

9. Shipsha A, Zenkert D (2005) Compression-after-Impact Strength of Sandwich Panels with Core Crushing Damage. Appl Compos Mater 12(3-4):149. doi:10.1007/s10443-005-1119-1. http://link. springer.com/10.1007/s10443-005-1119-1

10. Arora H, Hooper PA, Del Linz P, Yang H, Chen S, Dear JP (2012) Modelling the behaviour of composite sandwich structures when subject to air-blast loading. Int J Multiphys 6(3):199. doi:10.1260/1750-9548.6.3.199. http://multi-science.metapress. com/openurl.asp?genre=article $\% \mathrm{id}=\mathrm{doi}: 10.1260 / 1750-9548.6 .3$. 199

11. Jackson M, Shukla A (2011) Performance of sandwich composites subjected to sequential impact and air blast loading. Compos Part B 42(2):155. doi:10.1016/j.compositesb.2010.09.005. http:// linkinghub.elsevier.com/retrieve/pii/S1359836810001460

12. Wang E, Shukla A (2011) Blast Performance of Sandwich Composites with In-Plane Compressive Loading. Exp Mech 52(1):49. doi:10.1007/s11340-011-9500-5. http://link.springer. com/10.1007/s11340-011-9500-5
13. Viot P (2009) Hydrostatic compression on polypropylene foam. Int J Impact Eng 36(7):975. doi:10.1016/j.ijimpeng.2008.11.010. http://linkinghub.elsevier.com/retrieve/pii/S0734743X0800314X

14. Leijten J, Bersee HE, Bergsma OK, Beukers A (2009) Experimental study of the low-velocity impact behaviour of primary sandwich structures in aircraft. Compos A Appl Sci Manuf 40(2):164. doi:10.1016/j.compositesa.2008.10.019. http:// linkinghub.elsevier.com/retrieve/pii/S1359835X08002698

15. SPGurit. Corecell M-Series Data Sheets., www.gurit.com

16. Composites A. Airex C70 Data sheet (2011). www.3accorematerials.com

17. Industries E. Rohacell 110 SL Data sheet., www.rohacell.com

18. Technologies I. Innegra Data Sheets., www.innegratech.com

19. Materials A. E-Glass Properties., www.azom.com

20. Soden P, Hinton M, Kaddour A (1998) Lamina properties, layup con.gurations and loading conditions for a range of .brereinforced composite laminates. Combust Sci Technol 58. http:// www.sciencedirect.com/science/article/pii/S0266353898000785

21. Smith P, Hetherington J, Hetherington (1994) Blast and ballistic loading of structures, 1st edn. ButterworthHeinemann Ltd, Oxford. http://www.lavoisier.fr/livre/notice.asp? ouvrage $=1543030$

22. Arora H, Kelly M, Worley A, Del Linz P, Fergusson A, Hooper PA, Dear JP (1914) Proceedings of the Royal Society A: Mathematical, Physical and Engineering Sciences 89(612):411. doi:10.1098/rspa.1914.0008. http://rspa.royalsocietypublishing. org/cgi/doi/10.1098/rspa.1914.0008 